\title{
Prenatal ethanol exposure impairs the formation of radial glial fibers and promotes the transformation of GFAPS-positive radial glial cells into astrocytes
}

\author{
YU LI ${ }^{1,2^{*}}$, LI-NA ZHANG $^{3 *}$, LI CHONG $^{3}$, YUE LIU $^{3}$, FENG-YU XI $^{4}$, HONG ZHANG $^{1}$ and XIANG-LONG DUAN ${ }^{2,5}$ \\ ${ }^{1}$ Department of Infectious Diseases, Shaanxi Provincial People's Hospital and \\ The Affiliated Hospital of Xi'an Medical University; ${ }^{2}$ Shaanxi Center for Models of Clinical Medicine \\ in International Cooperation of Science and Technology; ${ }^{3}$ The Third Department of Neurology, \\ ${ }^{4}$ Department of Clinical Laboratory, Shaanxi Provincial People's Hospital and The Affiliated Hospital of \\ Xi'an Medical University; ${ }^{5}$ The Second Department of General Surgery, Shaanxi Provincial People's Hospital and \\ The Third Affiliated Hospital, School of Medicine, Xi'an Jiaotong University, Xi'an, Shaanxi 710068, P.R. China
}

Received July 18, 2020; Accepted January 12, 2021

DOI: $10.3892 / \mathrm{mmr} .2021 .11913$

\begin{abstract}
During embryonic cortical development, radial glial cells (RGCs) are the major source of neurons, and these also serve as a supportive scaffold to guide neuronal migration. Similar to Vimentin, glial fibrillary acidic protein (GFAP) is one of the major intermediate filament proteins present in glial cells. Previous studies confirmed that prenatal ethanol exposure (PEE) significantly affected the levels of GFAP and increased the disassembly of radial glial fibers. GFAPS is a variant of GFAP that is specifically expressed in RGCs; however, to the best of our knowledge, there are no reports regarding how PEE influences its expression during cortical
\end{abstract}

Correspondence to: Professor Hong Zhang, Department of Infectious Diseases, Shaanxi Provincial People's Hospital and The Affiliated Hospital of Xi'an Medical University, 256 Youyi West Street, Xi'an, Shaanxi 710068, P.R. China

E-mail: zhanghongxiyi@126.com

Professor Xiang-Long Duan, The Second Department of General Surgery, Shaanxi Provincial People's Hospital and The Third Affiliated Hospital, School of Medicine, Xi'an Jiaotong University, 256 Youyi West Street, Xi'an, Shaanxi 710068, P.R. China

E-mail: duanxlspph@126.com

${ }^{*}$ Contributed equally

Abbreviations: GFAP, glial fibrillary acidic protein; RGCs, radial glial cells; oRGs, outer radial glial cells; NSCs, neural stem cells; PEE, prenatal ethanol exposure; BACs, blood alcohol concentrations; VZ, ventricular zone; SVZ, subventricular zone; IZ, intermediate zone; SP, subcortical plate; CP, cortical plate; CNS, central nervous system

Key words: prenatal ethanol exposure, glial fibrillary acidic protein $\delta$, radial glial fiber, radial glial cells, embryonic cerebral cortex development. In the present study, the effects of PEE on the expression and distribution of GFAP during early cortical development were assessed. It was found that PEE significantly decreased the expression levels of GFAP and GFAPס. Using double immunostaining, GFAPd was identified to be specifically expressed in apical and basal RGCs, and was co-localized with other intermediate filament proteins, such as GFAP, Nestin and Vimentin. Additionally, PEE significantly affected the morphology of radial glial fibers and altered the behavior of RGCs. The loss of GFAPd accelerated the transformation of RGCs into astrocytes. Using co-immunostaining with $\mathrm{Ki} 67$ or phospho-histone $\mathrm{H} 3, \mathrm{GFAPd}^{+}$cells were observed to be proliferative or mitotic cells, and ethanol treatment significantly decreased the proliferative or mitotic activities of GFAPS ${ }^{+}$RGCs. Taken together, the results suggested that PEE altered the expression patterns of GFAPS and impaired the development of radial glial fibers and RGC behavior. The results of the present study provided evidence that GFAPS may be a promising target to rescue the damage induced by PEE.

\section{Introduction}

Prenatal ethanol exposure (PEE) is considered a significant risk factor underlying several functional and structural disorders, including stillbirth, spontaneous abortion, premature birth, intrauterine growth retardation and low birth weight, as well as developmental abnormalities of the central nervous system (CNS), which are collectively referred to as fetal alcohol spectrum disorders $(1,2)$. These deficits may result in lifelong behavioral abnormalities. In the human fetus, PEE-induced abnormalities exhibit several characteristics, including facial abnormalities, growth deficits, lowered intelligence and microcephaly $(3,4)$. In several animal models, including mouse (5), rat $(6)$, macaque $(7,8)$, zebrafish $(9)$ and chick models (10), PEE causes similar birth defects and permanent neurodevelopmental disorders. Although alcohol usage is preventable and a well-established hazard to the fetus, the global consumption of alcohol during pregnancy 
is still prevalent $(9.8 \%, 95 \%$ CI 8.9-11.1) $(1,2,11)$. As previously reported, alcohol usage is an urgent public health issue in China (12). A population-based Chinese study reported that pregnant women in China had a high prevalence rate of alcohol consumption $(6.2 \%$ in rural and $10.3 \%$ in urban areas), although women in China are discouraged from alcohol consumption (13). Therefore, it is important to investigate the mechanisms underlying the effects of prenatal ethanol or alcohol exposure on brain disorders.

Microcephaly is one of the major developmental brain defects associated with maternal ethanol exposure (14). PEE can result in a range of cortical dysfunctions, consisting of abnormal neuronal migration (15), reduced cell viability (16), changes to cortical thickness $(17,18)$ and loss of neurons $(8)$. Several factors are involved in the process of embryonic cortex development, such as morphogens, including fibroblast growth factor (19), bone morphogenetic protein 7 (20) and transforming growth factor $\beta 1(21,22)$, as well as Notch and Wnt signaling $(23,24)$, radial glial scaffolds for neuronal migration $(25,26)$ and cell-cell communications between cortical neurons and cortical precursor cells $(27,28)$. Among these, several studies have revealed that alterations of radial glial development contribute to the effects of alcohol on the development of the cortex (29-31). In vivo experimental results indicated that ethanol exposure decreases glial fibrillary acidic protein (GFAP) mRNA expression levels in the brains of pups from ethanol-fed Sprague Dawley or Wistar rat mothers and impairs the morphology of radial glial cells (RGCs) $(29,31)$. In vitro studies also revealed that ethanol could affect the distribution and content of the radial glial cytoskeletal proteins GFAP, Vimentin and Nestin (32). Thus, investigation of the effects of prenatal alcohol exposure on radial glial fiber proteins, such as Vimentin, Nestin and GFAP, may shed light on the mechanisms involved in alcohol-induced cortical malformation.

Previous studies have reported that neurogenesis occurs in two primary sites in the mammalian brain where the neural stem cells (NSCs) reside: The subventricular zone (SVZ) of the lateral ventricle and the subgranular zone (SGZ) of the hippocampal dentate gyrus (33). RGCs derived from neuroepithelial cells are ubiquitously present in the developing brain from the start of fetal neurogenesis until their final transformation into astrocytes in certain regions of the brain $(34,35)$. It has been confirmed that RGCs are specialized cells that can generate both neurons and astrocytes (34). In addition to the generation of neurons and intermediate progenitors, RGCs also provide radial glial scaffolding for neuronal migration via a long radial process $(36,37)$. As suggested by their name, RGCs have two characteristics: A long radial process, which spans the entire thickness of the wall of the neural tube and an (astro) glial property, which is indicated by the expression of glial proteins, including GFAP (38). Previous studies observed that GFAP-expressing neural progenitor cells are the major source of continuous neurogenesis (39-41). RGCs are ultrastructurally similar to astrocytes with regards to the expression of the filament protein GFAP and glycogen accumulation (42). During early cortical neurogenesis, GFAP expression is specifically found in RGCs, where co-localization with Vimentin and Nestin is also observed. However, GFAP positive cells exhibit a more lineage-restricted phenotype (34). Hence, the investigation of GFAP and the dynamic changes of its major variants, such as GFAP $\alpha$ and GFAPD, during the developmental process may elucidate the mechanisms underlying how GFAP regulates fetal cortical development.

In the present study, the developmental profile of GFAP $\delta$ was investigated in the cortex in the control and ethanol-exposed mice, with the aim of characterizing the roles of GFAPS in alcohol-induced cortex maldevelopment.

\section{Materials and methods}

Animals. Adult C57BL/6J mice (age, 8-12 weeks; mean body weight, $24.0 \pm 1.8 \mathrm{~g}$ ) were purchased from Hunan Silaike Jingda Laboratory Animal Co., Ltd. A single male mouse was housed with five female mice per standard polycarbonate cage. Mice were housed in a temperature- and humidity-controlled environment $\left(22^{\circ} \mathrm{C} ; 50 \%\right.$ humidity) with a 12 -h light/dark cycle. Before the initiation of the experiments, the mice were maintained with ad libitum access to standard laboratory chow and water. A total of 46 adults (male 6 and female 40) and 215 fetal mice were used in the present study. There were 14 dams and 102 fetuses in the ethanol (EtOH) group, and 14 dams and 113 fetuses in the Control group. There were 6 dams in the $\mathrm{EtOH}$ group and 6 dams in the Control group that were used specifically for a blood alcohol assessment. All animal maintenance and experimental procedures were approved by the Institutional Animal Care and Use Committee of Xi'an Medical University and animal experiments were performed in accordance with the National Institute of Health Guide for the Care and Use of Laboratory Animals (NIH Publications no. 80-23) (43).

Animal maintenance and ethanol acclimation. Before ethanol administration, the mice were acclimated for $\geq 1$ week after arrival. For the generation of the prenatal alcohol exposure models, female mice were fed on a liquid diet containing ethanol. The rodent liquid diet (Lieber-DeCarli '82, Bio-Serv 14-726-629 and 14-726-630) was purchased from Thermo Fisher Scientific, Inc. Control mice were maintained for the same period on the same diet without ethanol, but instead supplemented with maltodextrin to provide the appropriate amount of ethanol-derived calories. For alcohol exposure, the female mice were provided a Lieber-DeCarli liquid diet containing $2.4 \%(\mathrm{v} / \mathrm{v})$ ethanol for 2 days, then the ethanol concentration in the diet was increased to $4.8 \%$ (v/v) and maintained for a further 14 days; 5\% sucrose to Lieber-DeCarli liquid diet was added to increase palatability as described previously $(44,45)$. During alcohol exposure, the liquid diet was changed every day with a freshly prepared diet. After the acclimation/acquisition period for 16 days, the liquid diet was changed into normal laboratory chow and water for an ethanol deprivation period, during which the mice could recover from any potential alcohol withdrawal symptoms. This ethanol deprivation period averaged 16 days. During this ethanol deprivation period, the mice were bred by placing two females in a cage with one male for $1 \mathrm{~h}$ during the dark cycle and then were assessed for the presence of a copulation plug. If the plug was present, the time at the initiation of the 1-h mating period was considered as the gestational day (GD) 0 . On GD7.0 at the beginning of the dark cycle, the mice were provided a liquid diet containing ethanol $4.8 \%(\mathrm{v} / \mathrm{v}$, ethanol group) or a 
control liquid diet. The control liquid diet, which contained an isocaloric amount of maltodextrin instead of ethanol to meet the calories derived from ethanol, served as the pair-fed control. Maternal bodies were weighed, and diet consumptions were recorded based on the previous $24 \mathrm{~h}$ change of liquid diet from 30-ml graduated screw-cap tubes. Hence, the control and ethanol groups received the same amount of diet ( $\mathrm{ml})$ based on the $\mathrm{ml}$ diet per $\mathrm{g}$ body weight $(\mathrm{g})$. This matching of calorific content and diet feeding was to reduce the possible effects of any potential nutritional differences (44). Subsequently, the mice were maintained on this diet for $48 \mathrm{~h}$ through GDs 7 and 8 and returned to the standard laboratory chow and water until the fetuses were collected on GD14.

Maternal blood alcohol assessment. A set of dams was used to assess blood alcohol concentration (BAC). A total of $30 \mu 1$ tail blood was collected into heparinized capillary tubes from mice with sperm plugs on the 8th day of pregnancy (at 21:00 and 23:00 h). BACs were measured using an Analox alcohol analyzer (Model AM1; Analox Instruments USA, Inc.). For each time point, $\geq 3$ mice were sampled and analyzed, the total samples of each mouse were controlled for no more than three times. None of the fetuses from these animals were used for histological analysis or western blot analysis.

Collection of the embryos. On the morning of GD 14.0, the embryos of pregnant dams were collected after sacrifice using $\mathrm{CO}_{2}$ inhalation according to the NIEHS euthanasia methods for rodent fetuses and neonates (44). For $\mathrm{CO}_{2}$ asphyxiation, a clear acrylic chamber with a gasket lid (VWR International, LLC) was used. The total chamber volume was 21 (0.5 gal). The gas flow was set to $400 \mathrm{ml} / \mathrm{min}$ to achieve a $20 \%$ per min volume displacement rate. The death of the pregnant female mice was confirmed by the cessation of blood circulation (absence of heartbeat) and the absence of a breathing and pedal reflex. Fetal death was confirmed using ultrasound determination of the absence of a heartbeat. Subsequently, embryos were isolated from the uterus and extra-embryonic membranes under a dissecting microscope. The embryos were immersed in ice-cold 0.1 M 1X PBS. Tissues were fixed in 4\% PFA in $1 \mathrm{X}$ Dulbecco's (D)PBS overnight at $4^{\circ} \mathrm{C}$ with gentle shaking for immunohistochemistry. The dissected cortical tissues were collected and pooled from each dam for western blot analysis.

Protein extraction and western blot analysis. For protein extraction, the cortical tissues from mice embryos $(n=5-10$ samples per litter) were pooled and dissected, meninges were removed under a stereomicroscope and dissolved in $1 \mathrm{X}$ lysis buffer (Cell Signaling Technology, Inc.; cat. no. 9803) supplemented with $1 \mathrm{mM}$ PMSF. Subsequently, the tissues were mechanically homogenized with a tissue homogenizer and incubated on ice for $15 \mathrm{~min}$, followed by centrifugation at $12,000 \mathrm{x} \mathrm{g}$ for $15 \mathrm{~min}$ at $4^{\circ} \mathrm{C}$ to obtain the cleared supernatants. The supernatants were collected, and protein concentrations were measured using a Pierce ${ }^{\mathrm{TM}}$ BCA Protein assay kit (Thermo Fisher Scientific, Inc.; cat. no. 23225). The samples were then adjusted and dissolved in $2 \mathrm{X}$ Laemmli Sample buffer (Bio-Rad Laboratories, Inc.; cat. no. 1610737). Subsequently, the samples were boiled at $95^{\circ} \mathrm{C}$ for $5 \mathrm{~min}$, loaded on a $12 \%$ SDS-gel and resolved using SDS-PAGE; a
BLUEstain $^{\mathrm{TM}}$ Protein ladder (Goldbio; cat. no. P007-1500) was used to determine the molecular weight. The gels were blotted on PVDF membranes (Immobilon; EMD Millipore) at $200 \mathrm{~mA}$ for $1.5 \mathrm{~h}$ at $4^{\circ} \mathrm{C}$. A total of $15 \mu \mathrm{g}$ protein lysate was loaded into each well of the $12 \%$ SDS gel. After transferring and washing three times with PBS with $0.1 \%$ Tween $^{\circledR}$ detergent (PBST), 5 min per wash, the membranes were blocked using $3 \%$ bovine serum albumin (BSA; cat. no. ab64009, Abcam) in $1 \mathrm{X}$ PBST for $1 \mathrm{~h}$ at room temperature. Primary antibodies were diluted in $3 \%$ BSA-PBST buffer and incubated at $4^{\circ} \mathrm{C}$ on a shaker. After three washes (10 min each), the secondary horseradish peroxidase-conjugated anti-rabbit (1:2,000; cat. no. ab6721; Abcam) or anti-mouse antibodies (1:2,000; cat. no. ab6789; Abcam) were incubated with the membrane at room temperature for $1 \mathrm{~h}$. After three washes (10 min each), the membranes were developed using SuperSignal ${ }^{\mathrm{TM}}$ West Femto Maximum Sensitivity substrate (Thermo Fisher Scientific, Inc.; cat. no. 34096) and imaged using Image Lab $^{\text {TM }}$ Software Version 6.0.1 (Bio-Rad Laboratories, Inc.). For normalization, $\beta$-actin was used as the loading control. The following antibodies were used: Mouse anti-GFAP antibody (Sigma-Aldrich; Merck KGaA; cat. no. G3893; 1:2,000), rabbit anti-GFAPd antibody (Abcam; cat. no. ab93251; 1:2,000) or $\beta$-actin antibody (Abcam; cat. no. ab8227; 1:5,000). Densitometry analysis was performed using ImageJ version 1.6.0 (National Institutes of Health).

Embryo collections, fixation, sectioning and immunohistochemistry. On E14.5, control and ethanol-exposed mice were euthanized by $\mathrm{CO}_{2}$ inhalation, and cervical dissociation was performed. The maternal abdomen was opened and the fetuses were removed from the uterus. The number of fetuses was recorded and imaged for each litter using a digital camera (Micropublisher 5.0; Qimaging Corp.), which was mounted on an Olympus binocular dissecting microscope (Olympus America, Inc.).

For the histological analysis, the fetuses were collected from individual extraembryonic membranes and fixed in $4 \%$ paraformaldehyde (PFA, cat. no. 158127, Sigma-Aldrich; Merck KGaA) in 1 XDPBS overnight at $4^{\circ} \mathrm{C}$. After immersion in $30 \%$ sucrose in $1 \mathrm{X}$ DPBS, $20-\mu \mathrm{m}$-thick coronal sections were cut on a cryostat microtome (Leica CM3050 S; Leica Microsystems $\mathrm{GmbH}$ ). The sections were washed with PBS three times (each for $10 \mathrm{~min}$ ), then blocked using $10 \%$ donkey or goat serum (Abcam) in DPBS supplemented with $0.25 \%$ Triton X-100 (Sigma-Aldrich; Merck KGaA) for $2 \mathrm{~h}$ at room temperature. Sections were subsequently incubated with primary antibodies at $4{ }^{\circ} \mathrm{C}$ overnight. The following antibodies were used: Rabbit anti-SOX2 (Cell Signalling Technology, Inc.; cat. no. 23064; 1:200), mouse anti-Glial Fibrillary Acidic Protein (GFAP) antibody (Sigma; cat. no. G3893, 1:200), Mouse Anti-SOX2 antibody [9-9-3] (1:200; cat. no. ab79351; Abcam), rabbit anti-GFAPS antibody (1:200; cat. no. ab93251; Abcam), mouse anti-Hop antibody (E-1) (HOPX; Santa Cruz Biotechnology, Inc.; cat. no. sc-30216; 1:200), rabbit anti-Nestin antibody (1:200 cat. no. ab92391; Abcam), rabbit anti-Vimentin antibody (1:200; cat. no. ab92547; Abcam), mouse anti-S100 $\beta$ ( $\beta$-Subunit; Sigma-Aldrich; Merck KGaA; cat. no. S2532; 1:200), mouse anti-Ki67 antibody (Sigma-Aldrich; Merck KGaA; cat. no. MAB4190; 1:200) mouse anti-phospho-histone 

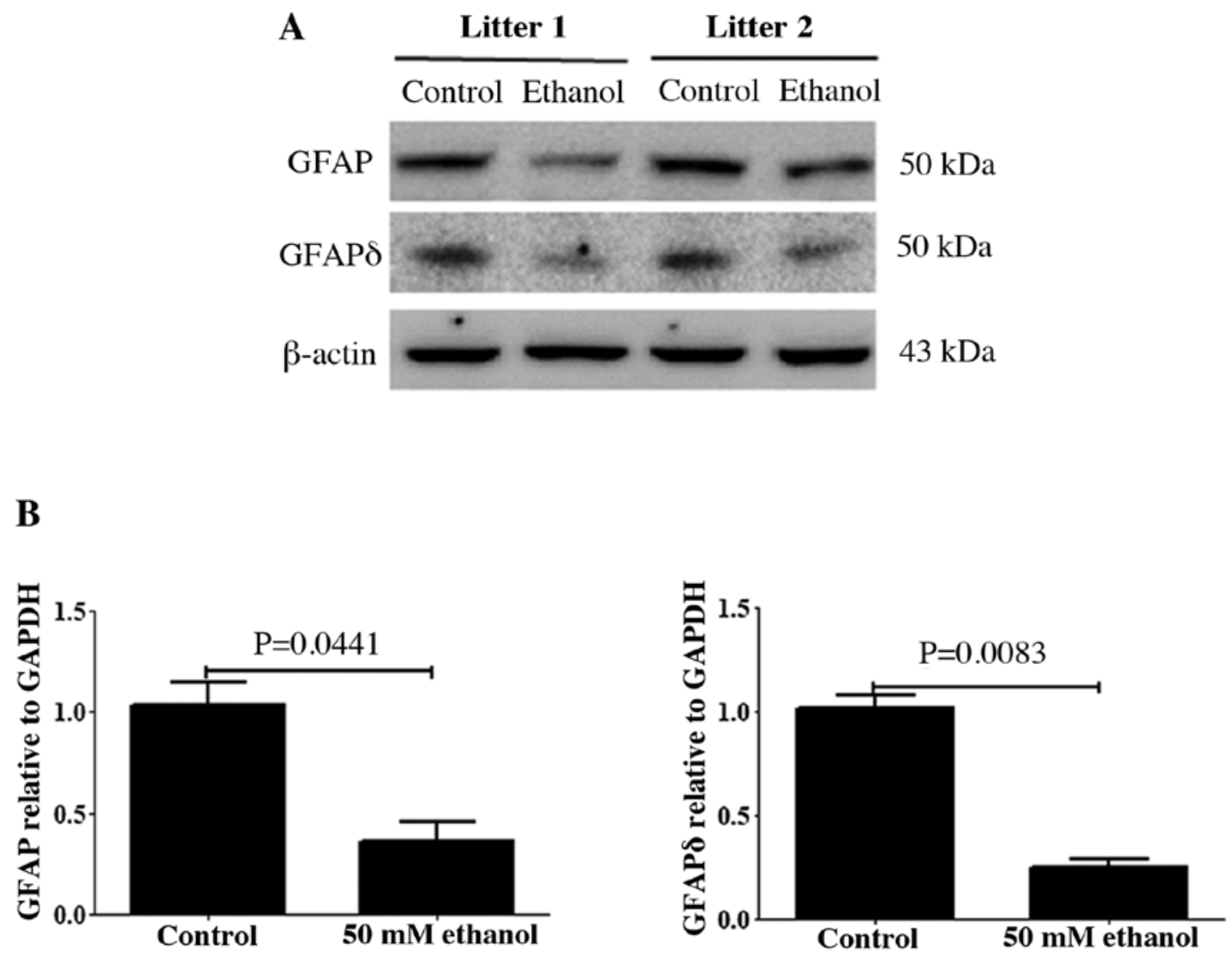

Figure 1. GFAP and GFAPס protein expression levels in control and prenatal ethanol exposure embryonic cortex. Western blot analysis was used to detect the expression levels of GFAP and GFAPס. Each line in the immunoblotting image represents one litter of mice. $\beta$-actin was used as a control. Values were normalized to those of the control group. Data are presented as the mean \pm SEM of offspring brains from six litters/group. (A) Expression levels of both GFAP and GFAPS. (B) Semi-quantitative densitometries for GFAP and GFAPS were normalized to $\beta$-actin levels. The data indicated that ethanol significantly decreased both GFAP and GFAPS expression levels. The P-value was obtained from an unpaired Student's t-test. GFAP, glial fibrillary acidic protein.

H3 (Ser10; 6G3) (pHH3; Cell Signaling Technology, Inc.; cat. no. 9706; 1:200), Rat anti-Ctip2 (1:200; cat. no. ab18465; Abcam). After washing three times with $1 \mathrm{X}$ DPBS, the fluorophore-conjugated secondary antibodies were used at a dilution of 1:200 and incubated for $2 \mathrm{~h}$ at room temperature. The secondary antibodies used were all purchased from Thermo Fisher Scientific, Inc. and were: Alexa Fluor 488 goat anti-rabbit IgG $(\mathrm{H}+\mathrm{L})$ Cross-Adsorbed Secondary antibody (cat. no. A11008) and Alexa Fluor 594 donkey anti-mouse IgG $(\mathrm{H}+\mathrm{L})$ Highly Cross-Adsorbed Secondary antibody (cat. no. A21203). Cell nuclei were counterstained at room temperature for 10 min with DAPI (Sigma-Aldrich; Merck KGaA; cat. no. D9542; 1:2,000). Subsequently, the slides were sealed and images were captured using a Nikon A1R confocal microscope (Nikon Corporation) with $\mathrm{x} 200$ magnification with the appropriate laser channels. Images were processed using ImageJ 1.50i (National Institutes of Health). The ventricular zone (VZ), SVZ, intermediate zone (IZ), subcortical plate (SP) and cortical plate $(\mathrm{CP})$ layers were delineated using DAPI staining.

Quantification of the proliferative or mitotic GFAP $\delta^{+}$ $R G C s$. The number of $\mathrm{Ki} 67^{+} \mathrm{GFAPd}^{+}$or $\mathrm{pHH}^{+} \mathrm{GFAP \delta}^{+}$ double-labeled cells, as well as total GFAPd ${ }^{+}$RGCs, were $^{+}$ quantified using ImageJ $1.50 \mathrm{i}$ with the co-localization finder plugin (46). For each brain region, six representative coronal sections were acquired using the Nikon A1R confocal microscope with $\times 200$ magnification. Of these images, three images were captured at the level of the ventricular surface, including the VZ and the inner SVZ. The other three images were captured above the initial images, including outer the SVZ, IZ and CP. Hence, cells were counted in $\sim 6$ images per brain region ( 6 images per region $\mathrm{x} 2$ brain regions per section $\mathrm{x} 4$ sections x 10 embryonic brains). Furthermore, the ratio of $\mathrm{Ki} 67^{+} \mathrm{GFAP \delta}^{+}$or $\mathrm{pHH}^{+} \mathrm{GFAP \delta}^{+}$cells to total $\mathrm{GFAP \delta}^{+}$cells was calculated.

Statistical analysis. For quantification of immunostaining, the images were processed in parallel and were captured using the same settings and laser power for confocal microscopy. The cell numbers were manually counted using the ImageJ $1.50 \mathrm{i}$ cell counter plugin (National Institutes of Health). The fluorescence intensity was measured using ImageJ $1.51 \mathrm{i}$ and normalized to the size of the aggregates. All quantitative results are presented as the mean \pm SEM. To determine the statistical difference, an unpaired Student's t-test was performed. $\mathrm{P}<0.05$ was considered to indicate a statistically significant difference. Experiments were repeated at least three times.

\section{Results}

Ethanol intake and blood concentration measurements. The aforementioned ethanol exposure protocol resulted in an 
A Control Ethanol

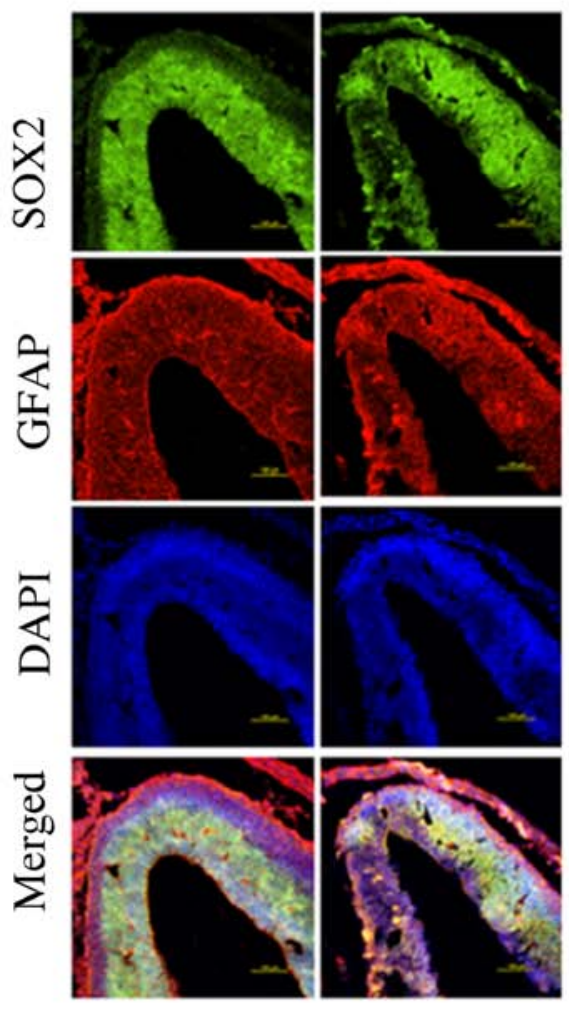

C

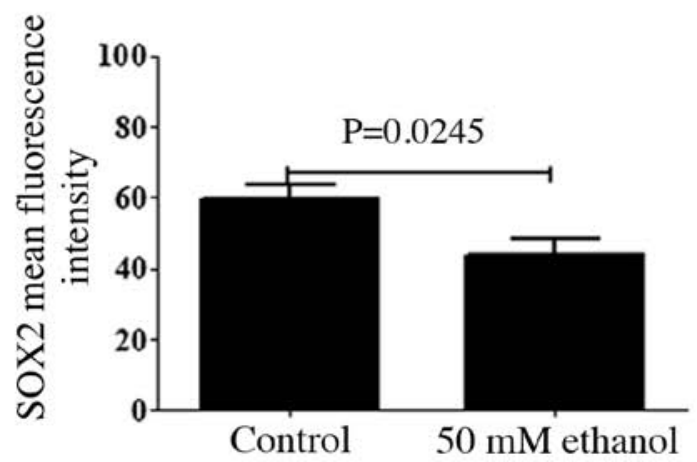

B

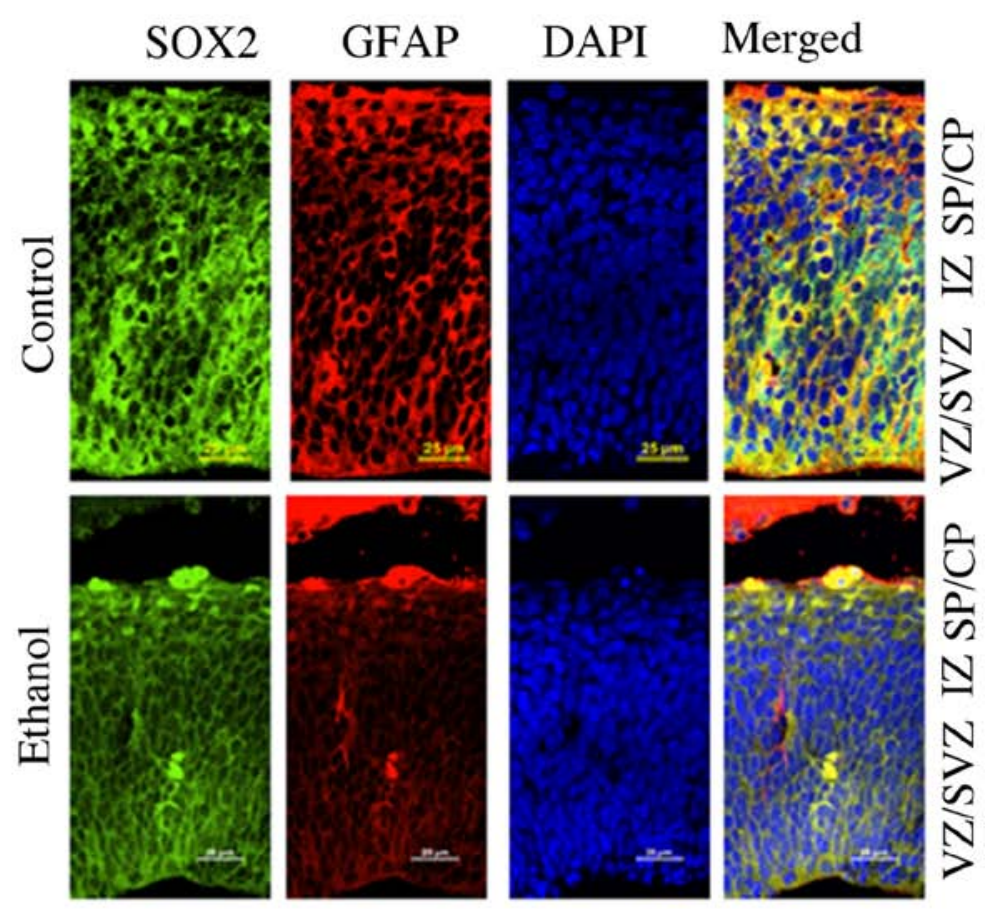

D

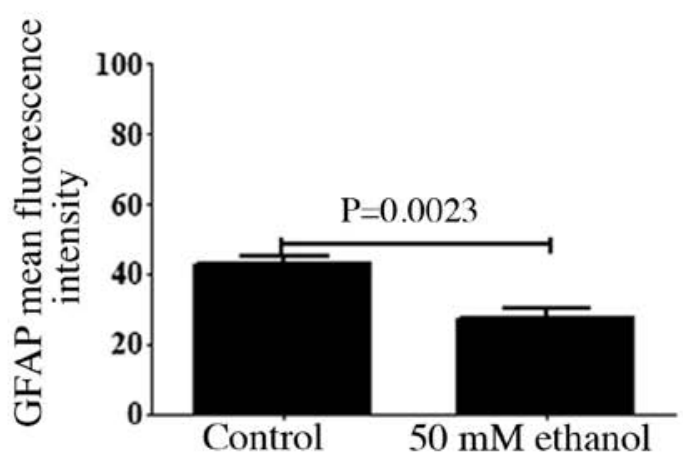

Figure 2. Effects of PEE on the expression level of GFAP in radial glial cells. (A) Coronal sections of control and PEE treated brain was stained with DAPI (blue), SOX2 (green), and GFAP (red). Immunostaining revealed the distributions of SOX2-positive neural progenitors and GFAP-positive cells in control and PEE-treated cortices. (B) The distribution of SOX2 and GFAP in cortical layers. Serial sections of embryonic cortices were double immunostained with the antibodies against SOX2 (green) and GFAP (red). Images indicated that GFAP was expressed in the whole embryonic cortex layers and colocalized with SOX2 in control group. PEE decreased the colocalization of SOX2 and GFAP. Quantification of mean fluorescence intensity of (C) SOX2 and (D) GFAP. PEE significantly decreased the numbers of SOX2 ${ }^{+}$GFAP ${ }^{+}$radial glial cells. Scale bars, $100 \mu \mathrm{m}$ (A) and $25 \mu \mathrm{m}$ (B). The P-value was obtained from an unpaired Student's t-test. PEE, prenatal ethanol exposure; GFAP, glial fibrillary acidic protein; SP, subcortical plate; CP, cortical plate; IZ, intermediate zone; VZ, ventricular zone; SVZ, subventricular zone.

average ethanol intake on GD8 of $25.1 \mathrm{~g} / \mathrm{kg} / \mathrm{day}$. This mean amount of ethanol intake resulted in BACs of $168-216 \mathrm{mg} / \mathrm{dl}$ (mean; $178.4 \mathrm{mg} / \mathrm{dl}$ ).

Western blot analysis of GFAP and GFAPD expression levels in the cortex. GFAP and its variant GFAPd are two major components of radial glial fibers, and both proteins are expressed in RGCs (41). The relative expression levels of GFAP and GFAPS in the control and PEE brain on E14.5 were analyzed using western blotting. As presented in Fig. 1A, immunoblots of GFAP and GFAPS showed a single band of $\sim 50 \mathrm{kDa}$, which corresponded to the molecular mass of GFAP and GFAPS. After PEE, the relative densities of GFAP and GFAPס were significantly decreased compared with those of the controls (Fig. 1B).

Effects of PEE on the expression of GFAP in RGCs. To assess the effects of ethanol exposure on the distribution of GFAP, cortical sections were fixed and co-immunostained for SOX2 and GFAP using the corresponding antibodies. The results 

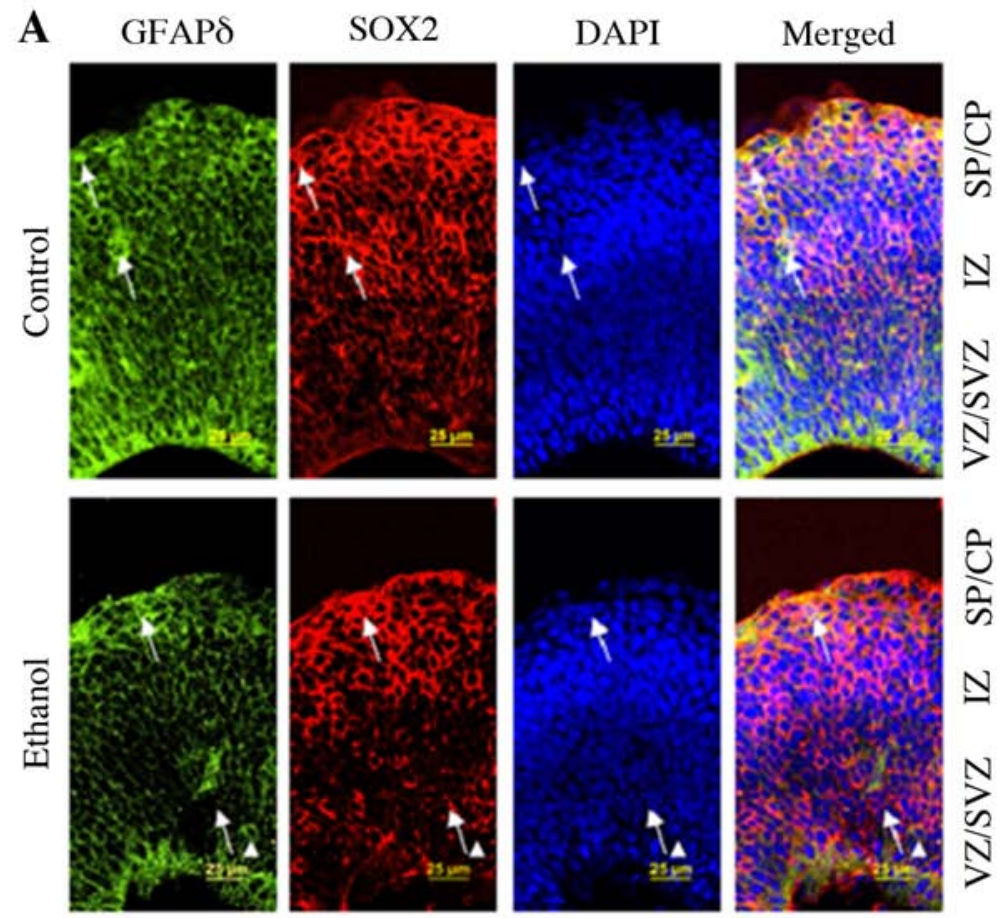

B
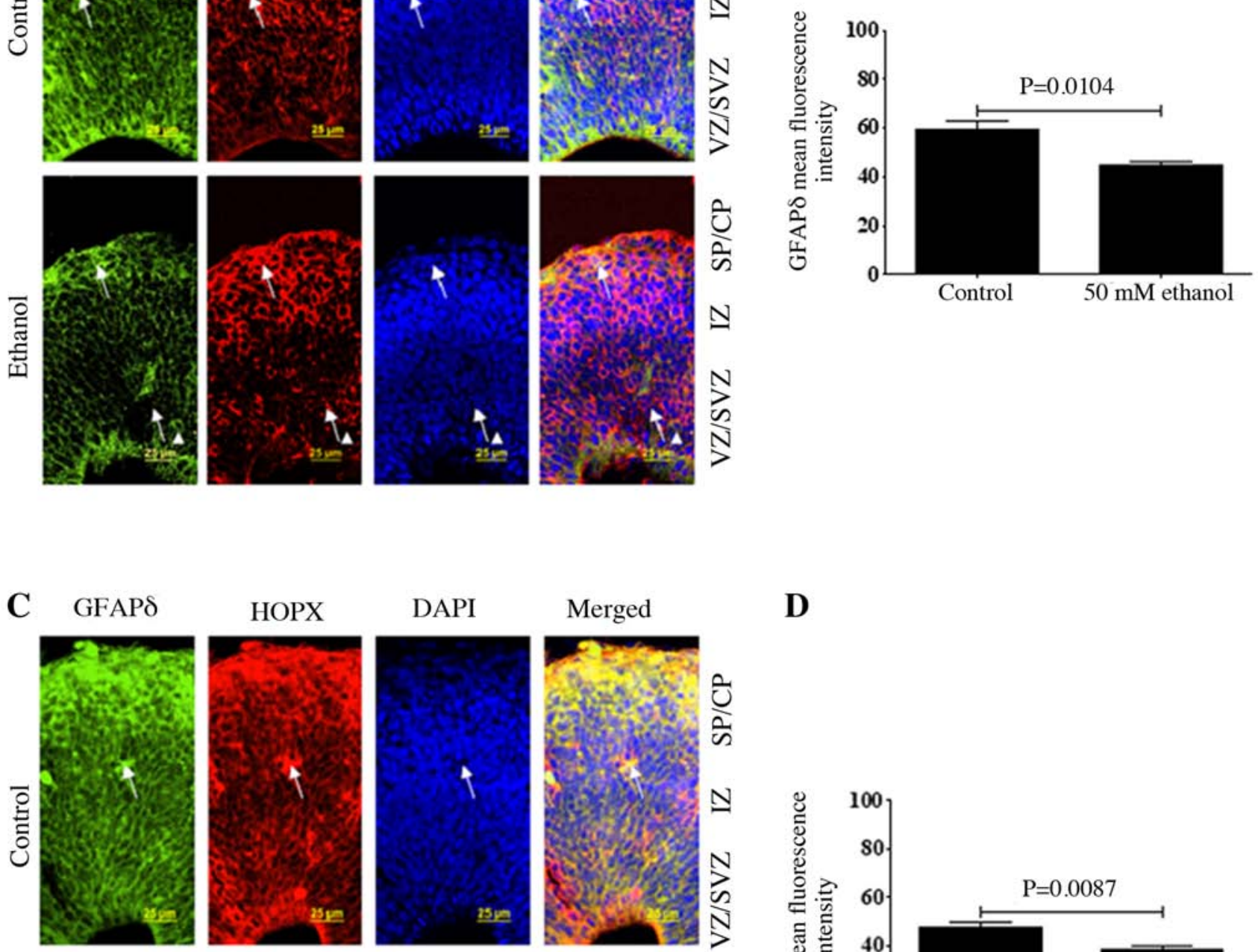

Merged
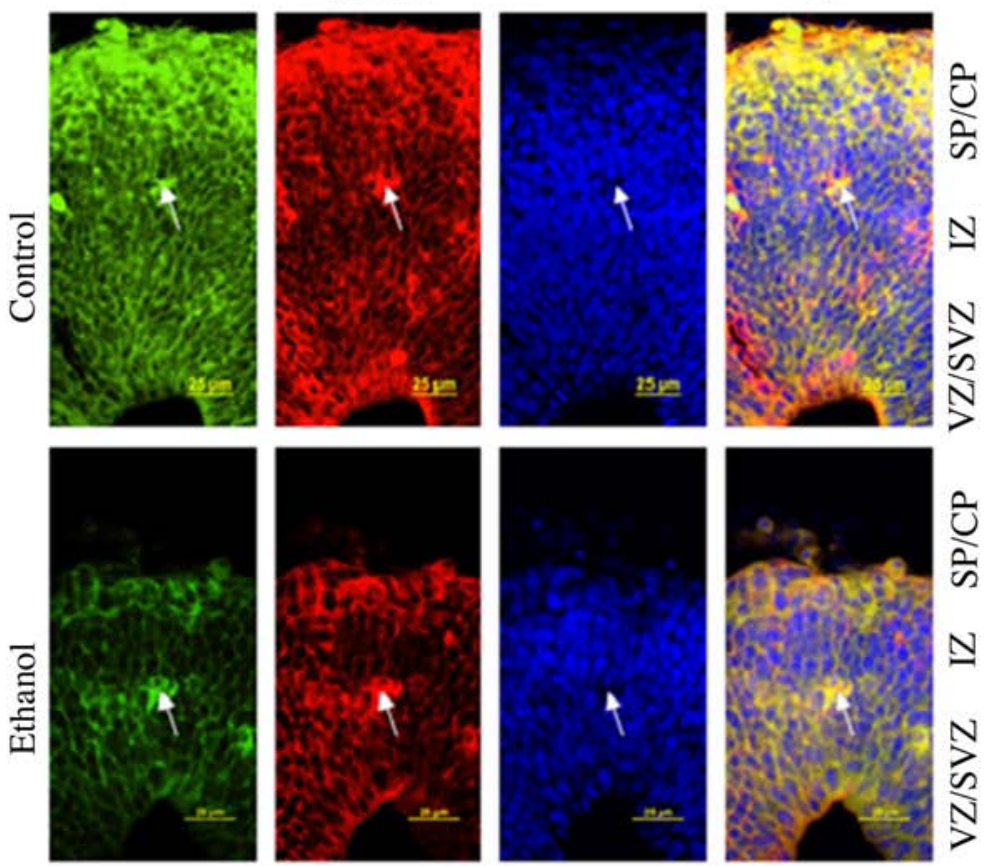

D

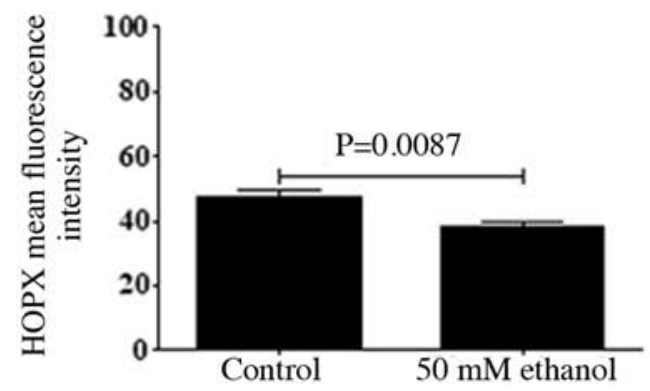

Figure 3. Effects of PEE on the expression level of GFAPd in radial glial cells. Serial sections of embryonic cortices were subjected to the antibodies against GFAPS and (A) radial glial marker SOX2 or (C) outer radial glial marker HOPX. At embryonic day 14.5, cells with overlapping expression levels of GFAPS and SOX2 were shown in yellow. The nuclear stain was in blue. The data indicated that GFAPS ${ }^{+}$cells were also co-labeling with SOX2. Arrows pointed

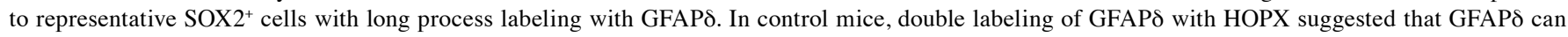
also be expressed in outer radial glial cells. PEE decreases the intensity of GFAPס in (B) SOX2 and (D) HOPX positive cells as shown in the right panels, indicating that PEE decreases the stem cell potential of radial glial cells. Scale bars, $25 \mu \mathrm{m}$. The P-value was obtained from an unpaired Student's t-test. PEE, prenatal ethanol exposure; GFAP, glial fibrillary acidic protein; SP, subcortical plate; CP, cortical plate; IZ, intermediate zone; VZ, ventricular zone; SVZ, subventricular zone; HOPX, Hop antibody (E-1).

demonstrated that $\mathrm{SOX}_{2}{ }^{+}$cells were predominantly present in the $\mathrm{VZ}$ and $\mathrm{SVZ}$, where almost all cells were $\mathrm{SOX}^{+}$, and only a few $\mathrm{SOX}^{+}$cells in the IZ were present (Fig. 2). Moreover, few cells were $\mathrm{SOX}^{+}$in the SP/CP. SOX2 $2^{+}$cells also co-express GFAP. At E14.5, GFAP ${ }^{+}$cells were observed in all layers. Some ventricular $\mathrm{GFAP}^{+}$cells showed the characteristic 
A
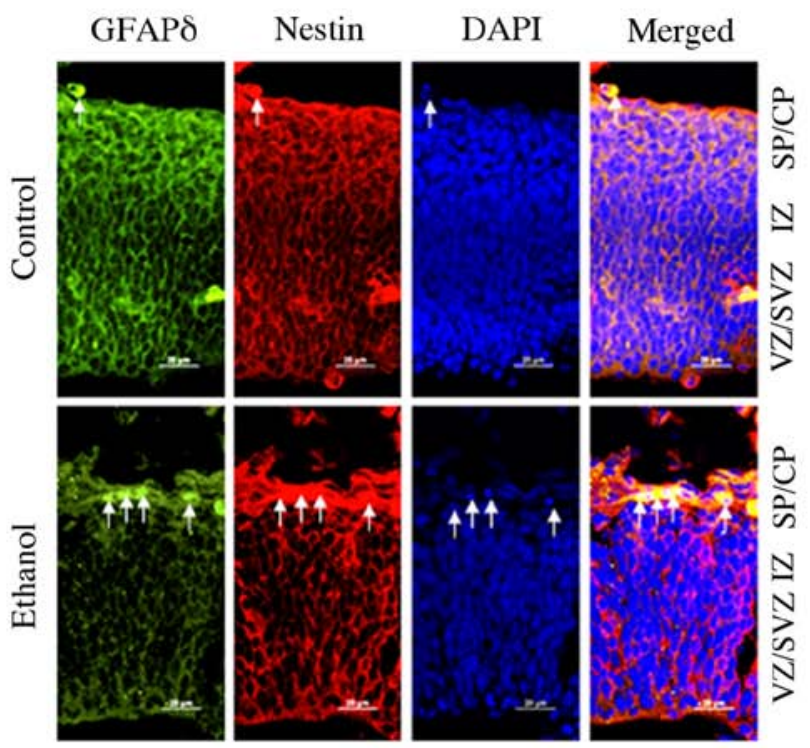
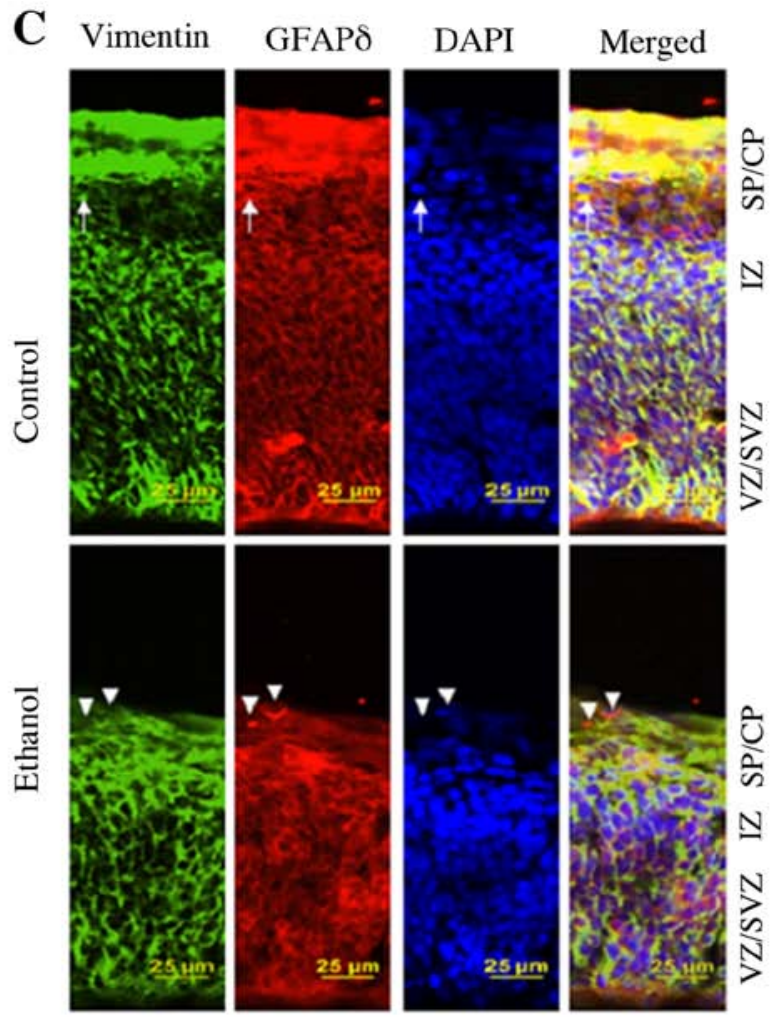

D

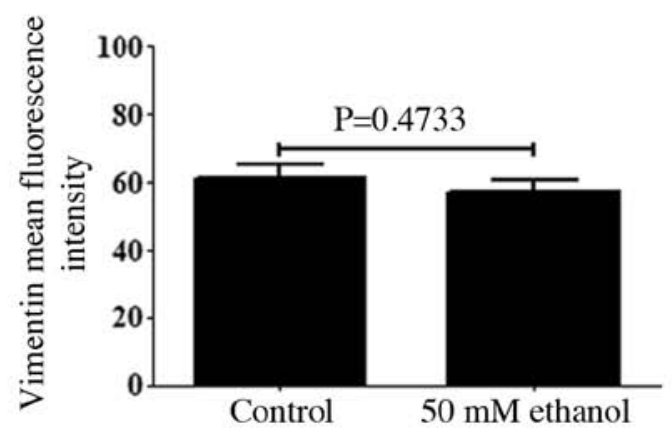

Figure 4. Effects of PEE on the co-immunostaining of Nestin or Vimentin in GFAPd ${ }^{+}$cells. Serial sections of embryonic cortices were subjected to the

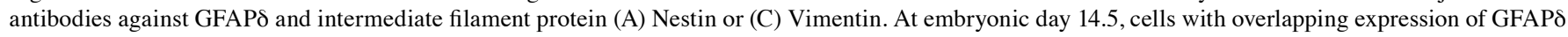
and Nestin or Vimentin were shown in yellow. The nuclear stain was blue. The present data indicated that Nestin immunostaining had similar distribution as GFAPS, which was surrounding the nuclear. In control mice, double immunostainings of GFAPS and Nestin or Vimentin indicated colocalization of two immunoreactivities in most of the cells, as indicated by arrows. Quantification of mean fluorescence intensity of (B) Nestin and (D) Vimentin. PEE promoted the early appearance of GFAPS ${ }^{+}$astrocytes in the SP, as shown by single GFAPd staining indicated by white arrowheads. It was indicated that PEE impaired the intermediate filamentous components of radial glial fibers and promoted the terminal differentiation of radial glial cells. Scale bars, $25 \mu$ m. The P-value was obtained from an unpaired Student's t-test. PEE, prenatal ethanol exposure; GFAPס, glial fibrillary acidic protein $\delta$; SP, subcortical plate; CP, cortical plate; IZ, intermediate zone; VZ, ventricular zone; SVZ, subventricular zone.

morphologies of RGCs with an endfoot contacting the ventricular surface, a cell body within the ventricular zone and a long basal process extending toward the pia. Following ethanol treatment, the fluorescence intensities of both SOX2 and GFAP were significantly decreased (Fig. $2 \mathrm{~B}$ and $\mathrm{C}$ ), suggesting that ethanol exposure decreased the stem cell potential of RGCs.

Effect of PEE on the expression of GFAPS in RGCs. As GFAP $\delta$ expression was specifically limited to RGCs in the neurogenic regions, whether GFAPS was co-expressed with the well-defined neural stem cell marker SOX2 and outer RGC (oRG) marker, HOPX expression was next determined.
To confirmed the specificity of GFAPס, GFAPס and CTIP2 were co-immunostained and it was found that GFAP $\delta$ was not expressed in CTIP2-positive neurons (Fig. S1). The results demonstrated that GFAPS had similar expression patterns with SOX2 and HOPX (Fig. 3). As a marker of oRG, HOPX was predominantly expressed in the VZ, SVZ and CP as indicated by the arrow in Fig. 3C. Double staining identified that GFAPS expression strongly overlapped with both SOX2 and HOPX. Furthermore, the quantitative data indicated that ethanol treatment could significantly decrease the fluorescence intensity of GFAPS and HOPX (Fig. 3B and D), suggesting that PEE could disrupt the assembly of oRG fibers. 
A

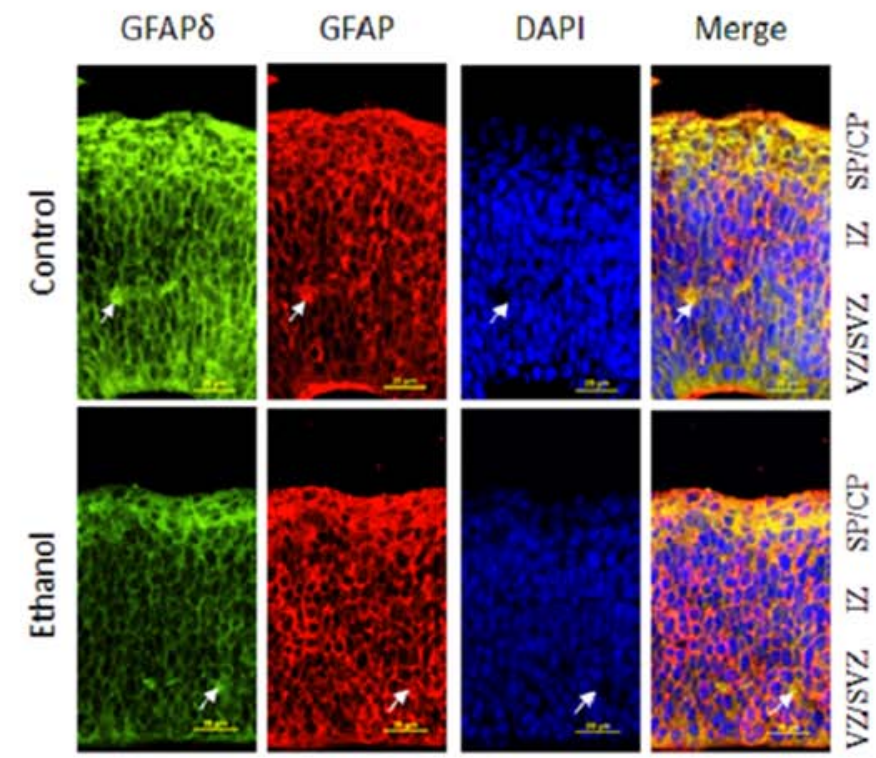

B

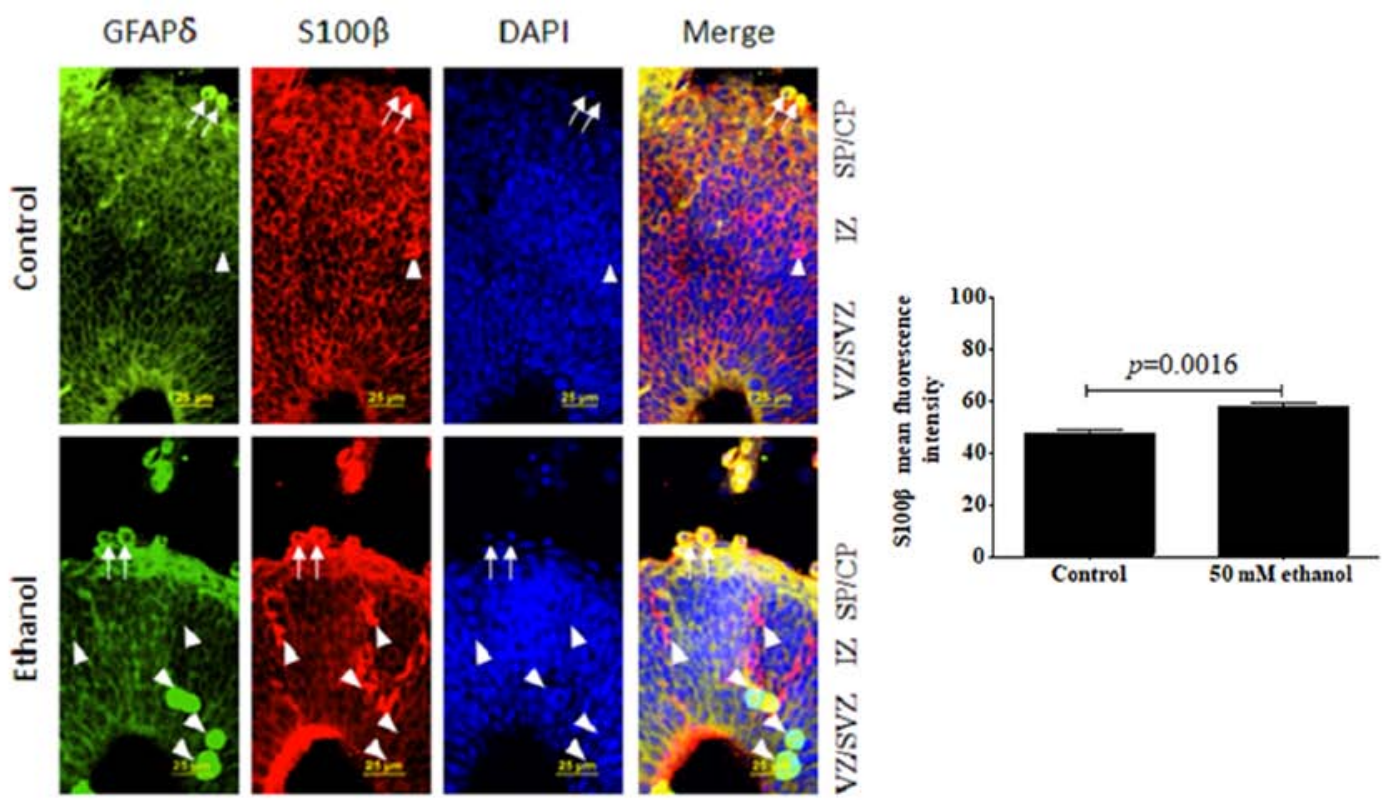

Figure 5. Effects of PEE on the co-immunostaining of GFAPd and GFAP or S100 $\beta$ in radial glial cells. Serial sections of embryonic cortices were double

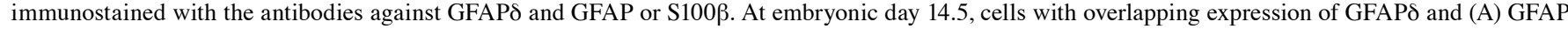
or (B) S100 $\beta$ are shown in yellow. The nuclear stain is blue. The results suggested that GFAP cells exhibited long processes in control group. In control mice, double labelling of GFAP $\delta$ and GFAP or S100 $\beta$ revealed the colocalization of the two immunoreactivities. PEE notably decreased the expression of GFAPD in GFAP-positive cells and increased the expression of S100 $\beta$ in GFAP $\delta$-positive cells. Arrows indicated cells that have double staining of GFAP $\delta$ and GFAP or S100 $\beta$ in both the control and PEE cortex. Arrowheads showed cells had only express S100 $\beta$ or GFAP $\delta$. It was indicated that PEE enhanced the maturation of $\mathrm{GFAP}^{+}$radial glial cells. (C) Quantification of mean fluorescence intensity of S100 $\beta$ in control and ethanol groups. Scale bar, $25 \mu \mathrm{m}$. The P-value was obtained from an unpaired Student's t-test. PEE, prenatal ethanol exposure; GFAP, glial fibrillary acidic protein; SP, subcortical plate; CP, cortical plate; IZ, intermediate zone; VZ, ventricular zone; SVZ, subventricular zone.

Effect of PEE on co-localization of GFAPd with Nestin or Vimentin in RGCs. To determine whether PEE could impair other intermediate filament proteins, the expression distribution of Nestin and Vimentin was also assessed. The results demonstrated that Nestin was expressed on both the apical and basal surface processes of the RGCs, and its expression was co-localized with GFAP $\delta$ and surrounded the nuclei, similar to GFAPD. Ethanol treatment significantly decreased both Nestin and GFAPd expression (Fig. 4A and B). In the SVZ and IZ layers, Nestin expression, based on fluorescence intensity, was significantly decreased following ethanol exposure (Fig. 4B). Similar to Nestin, Vimentin expression was also co-localized with GFAP $\delta$ in the apical and basal surfaces of the process from the RGCs (Fig. 4C). Several RGCs in VZ showed strong Vimentin-positive apical processes. The majority of Vimentin-immunostaining encircled the nuclei of the cells 
and labeled the fibers of RGCs. At E14.5, Vimentin, similar to GFAPD, was observed across almost the entire cortical wall. Compared with the staining of GFAPS around the cell nucleus, Vimentin was more concentrated in the process of the RGCs. Ethanol exposure decreased the expression of Vimentin, as indicated by the presence of $\mathrm{GFAPS}^{+}$Vimentin $^{-}$cells (Fig. 4C). Although ethanol exposure resulted in a slight decrease in the fluorescence intensity of Vimentin, there was no significant difference compared with control (Fig. 4C).

PEE decreases GFAP and GFAPD protein expression levels in RGCs and promotes their maturation. According to previous reports, GFAP is a defined marker protein of astrocytes $(40,47)$. To determine whether GFAPd expression was similar to the GFAP expression in the developing cortex, double staining of GFAP $\delta$ together with GFAP was performed. The results demonstrated that both GFAP and GFAP $\delta$ were detected in the cortex at E14.5. These exhibited similar expression patterns in the developing VZ and SVZ, as well as the superficial layers, IZ and CP. GFAPD-positive cells had a bipolar morphology with the soma in the VZ, short processes toward the ventricles and longer processes extending toward the CP (Fig. 5). Moreover, GFAPS filaments were tangentially oriented, exhibiting unipolar or bipolar morphologies. From the staining, it was identified that GFAPS filaments localized to the cell body and peri-nuclear regions. Similarly, GFAP was also observed both in the somata and processes of RGCs, which overlapped with the pattern of GFAP $\delta$ expression. Both GFAP and GFAPס could be detected in the superficial layers at E14.5. Some GFAP ${ }^{+}$RGCs exhibited only the basal processes, resembling basal RGCs of the neocortex (arrow; Fig. 5A). After ethanol treatment, the expression levels of both GFAP and GFAPD were significantly decreased. In the SVZ region after ethanol exposure, there were some GFAP ${ }^{+}$ $\mathrm{GFAPS}^{+}$cells without apical and basal processes, and these would have eventually become astrocytes. Apical radial glia in the VZ had notable $\mathrm{GFAP}^{+} \mathrm{GFAP}^{+}$staining compared with that of the control, which suggested ethanol treatment significantly influenced the formation of radial glial fibers. Thus, altering the expression of GFAP and GFAP $\delta$ may be how ethanol consumption during fetal cortical development exerts its detrimental effects.

It was hypothesized that loss of GFAP and GFAPd may promote terminal differentiation of RGCs. S100 $\beta$ can be considered as a marker of the progression of neural progenitors. To evaluate whether GFAP $\delta$ could colocalize with S100 $\beta$, double staining of GFAPd and S100 $\beta$ was performed. Interestingly, $\mathrm{S} 100 \beta$ exhibited similar distribution patterns through all the layers of cortex with that of GFAPd (Fig. 5B), and its expression was localized to the perinuclear area. The ethanol-exposed brain showed a significantly increased intensity of cytoplasmic staining compared with the control (Fig. 5C). However, there were more concentrated particles in RGCs in the ethanol group. Unlike GFAP immunostaining, $S 100 \beta$ is a protein that can reliably define the maturation stage of $\mathrm{GFAP}^{+}$cells (48). Increased expression of $\mathrm{S} 100 \beta$ in the developmental RGCs indicated the loss of stem cell differentiation potential by ethanol exposure. Quantification analysis demonstrated that ethanol resulted in a significant upregulation of S100 $\beta$ in the VZ and CP. Thus, it was suggested that
$\mathrm{GFAPS}^{+}$RGCs gradually lost their stem cell potential and became more restricted following ethanol treatment.

Effects of PEE on the proliferative or mitotic abilities of GFAPD-positive cells. To determine whether GFAPS positive cells were proliferative cells or dividing cells, the colocalization of GFAPס with Ki67 (Fig. 6A and B) or pHH3 (Fig. 7A and B) was detected. The results demonstrated that GFAPD-expressing cells expressed the proliferation marker Ki67 or mitotic marker pHH3 in both the control and ethanol groups. PEE remarkably inhibited the proliferative and mitotic activities of GFAPD-positive cells compared with that of the control group. Furthermore, GFAPd ${ }^{+}$proliferative cells were distributed in all the layers. The proliferative cells had both basal and apical processes in the VZ region, suggesting these cells were apical RGCs. In the SVZ, the $\mathrm{Ki} 67^{+}$proliferative cells had their basal processes extending to the $\mathrm{CP}$, which is one of the characteristic morphologies of oRG cells (Fig. 6A). Hence, the GFAPS ${ }^{+} \mathrm{Ki} 67^{+}$cells were considered active RGCs.

Regarding the co-expression of GFAPd and pHH3, most of the $\mathrm{GFAPS}^{+}$cells exhibited active mitotic activities. $\mathrm{pHH}^{+}$ mitotic cells were distributed in almost all the layers including the VZ, SVZ and CP. Ethanol treatment significantly affected the colocalization of GFAPS and $\mathrm{pHH} 3$, particularly in the SVZ region (Fig. 7A). Following alcohol treatment, the ratio of co-localization of $\mathrm{GFAPS}^{+} \mathrm{Ki} 67^{+}$or $\mathrm{GFAP}^{+} \mathrm{pHH}^{+}$to total $\mathrm{GFAP}^{+}$cells was significantly decreased (Figs. 6B and 7B).

\section{Discussion}

During the developmental process of the dorsal telencephalon, RGCs and intermediate progenitor cells are the primary sources of excitatory neurons (49). SOX2 is a Sry-related HMG-box-type transcription factor, which is important for the maintenance of stem cell differentiation potential (50). SOX2 is a well-known and key regulator of cell fate decisions during neurogenesis, and it is important for the maintenance of the proliferative potential and the supervision of the generation of subpopulations of cells with varying phenotypes in the developing neocortex (51). A high expression level of SOX2 autonomously maintains stem cell potential, inhibits neuronal differentiation and maintains progenitor characteristics (49). Moreover, inhibition of SOX2 results in a loss of expression of progenitor markers and enhances early neuronal differentiation (50). Using conditional deletion, it has been revealed that SOX2 deletion could significantly influence the embryonic development of the ventral telencephalon (52). Thus, SOX2 is a key regulator between the stem cell and the dividing progenitors $(53,54)$. It was previously confirmed that SOX2 is specifically expressed in neural epithelial cells and RGCs, but not in intermediate progenitor cells (49), thus it is considered a radial glial marker protein. Following the process of differentiation, SOX2 expression is decreased during the final fate decision of stem cells. During cortical development, SOX2 can be expressed together with GFAP in RGCs within the neurogenic regions SVZ and SGZ (39). In the present study, the findings demonstrated that prenatal ethanol exposure resulted in a significant decrease in both the number of $\mathrm{SOX}^{+}$cells and the intensity of GFAPd and GFAP expression in $\mathrm{SOX}^{+}$cells. 
A
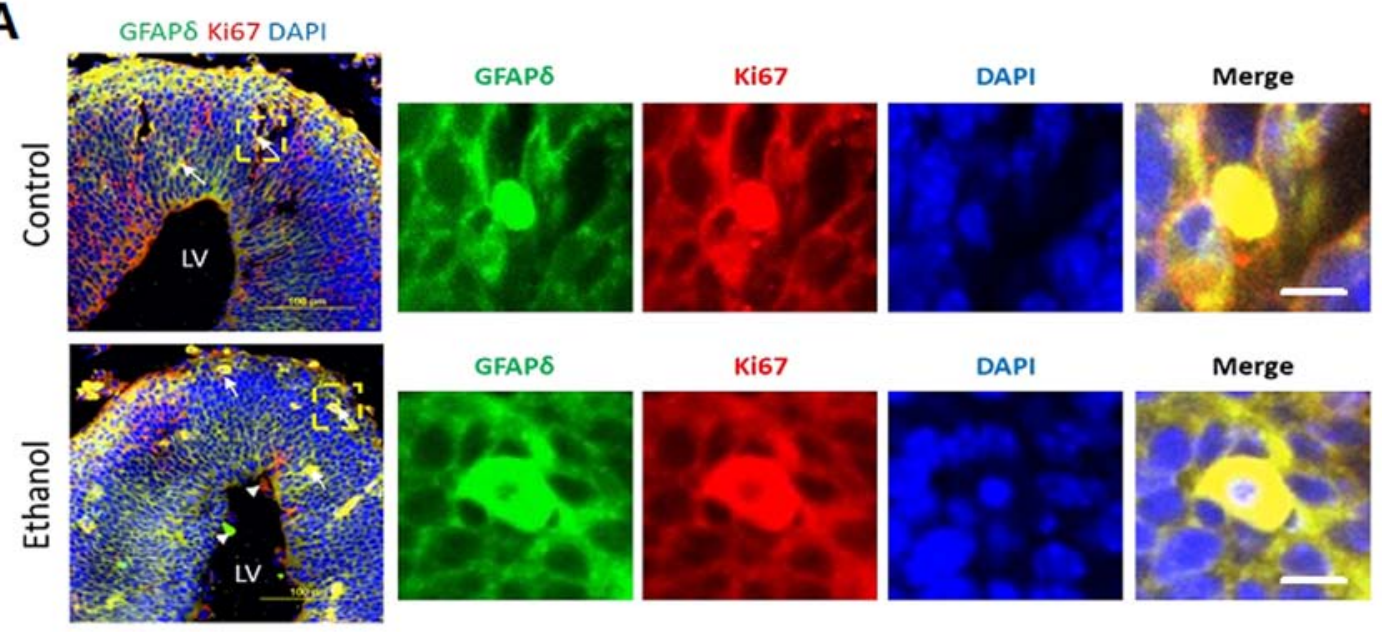

B

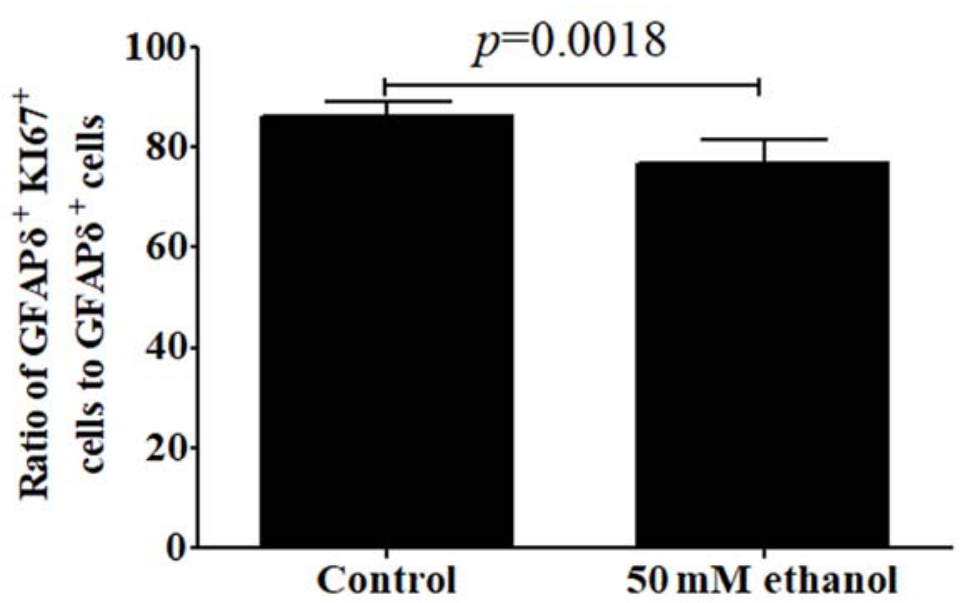

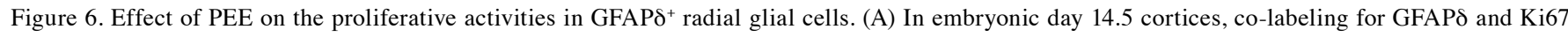
demonstrated that $\mathrm{GFAP \delta}^{+}$cells were proliferating RGCs in the VZ, SVZ, IZ or CP. PEE significantly influenced the distribution of Ki67 $7^{+}$cells. In the ethanol cortex, radial glial cells were less abundant for GFAP ${ }^{+} \mathrm{Ki} 67^{+}$cells. The arrows indicate examples of $\mathrm{GFAP}^{+} \mathrm{Ki} 67^{+}$proliferative cells located in the control and ethanol-treated cortex. Arrowheads show the single labeling cells by GFAPס or Ki67 in the ethanol-treated embryonic cortex. Immunostainings for representative GFAPS ${ }^{+} \mathrm{Ki}^{+} 7^{+}$proliferative cells in control and ethanol groups are showed in the right magnification images. (B) Quantification of the ratio of $\mathrm{GFAP \delta}^{+} \mathrm{Ki} 7^{+}$positive cells to total $\mathrm{GFAP \delta}^{+}$cells in the cortical layers. Scale bar, $100 \mu \mathrm{m}$ (Left image) and $10 \mu \mathrm{m}$ (right magnification images). The P-value was obtained from an unpaired Student's t-test. PEE, prenatal ethanol exposure; GFAP, glial fibrillary acidic protein; SP, subcortical plate; CP, cortical plate; IZ, intermediate zone; VZ, ventricular zone; SVZ, subventricular zone; LV, lateral ventricle.

Radial glial fibers are highly dynamic and are cell specific, providing the scaffold for neuroblast migration during normal neurodevelopment $(25,26)$. Radial glial fibers promote the postnatal ventricular-subventricular zone (v-svz)-derived neuroblast to migrate toward to the lesion sites (36). GFAP is one of the major intermediate filament proteins in RGCs and astrocytes, which can colocalize with several other intermediate filaments, such as Vimentin and Nestin $(41,55)$. Previous studies have confirmed that increased expression of intermediate filament proteins is an important step in the formation of reactive astrocytes $(47,56,57)$. Dividing GFAP-expressing cells with bipolar or unipolar morphologies are considered RGCs in the human forebrain (58). In rodent models, GFAP expression is only detected in the astrocytic lineage after neurogenesis has ended and Vimentin expression is no longer detectable (58). GFAP is a member of class III intermediate filament proteins. There are 10 different transcripts of the GFAP gene and these can generate 10 differential splicing variants: GFAP $\alpha$, GFAP $\beta$, GFAP $\gamma$, GFAPd,
GFAP $\kappa$, GFAP $\zeta$, GFAPD135, GFAPD164, GFAPDexon6 and GFAPDexon7 $(56,59)$. All these variants are similar, and the differences primarily reside in the $\mathrm{C}$-terminal tail region. GFAP $\alpha$ is the most widely expressed protein. Moreover,GFAPd expression is limited to specialized astrocyte populations and is more abundant in neurogenic regions, such as the SVZ of the lateral ventricle, the rostral migratory stream, the SGZ of the hippocampus and the subpial astrocytes $(39,41,55,56)$. GFAPS positive cells are specifically restricted to these neurogenic areas, where expression of Nestin and Vimentin is also observed, suggesting that GFAPS may be a RGC-specific filament protein that is required for their substrate functions and may be a determining factor associated with neurogenesis $(55,60)$. The ratio of GFAP $\alpha$ and GFAP $\delta$ is an important factor in the formation of the intermediate filament network, which is closely associated with cellular functions (such as neurogenesis) or cellular morphology (such as gliosis) (56). The changes in the expression levels of the GFAP splice variants could significantly influence the intermediate filament 
A
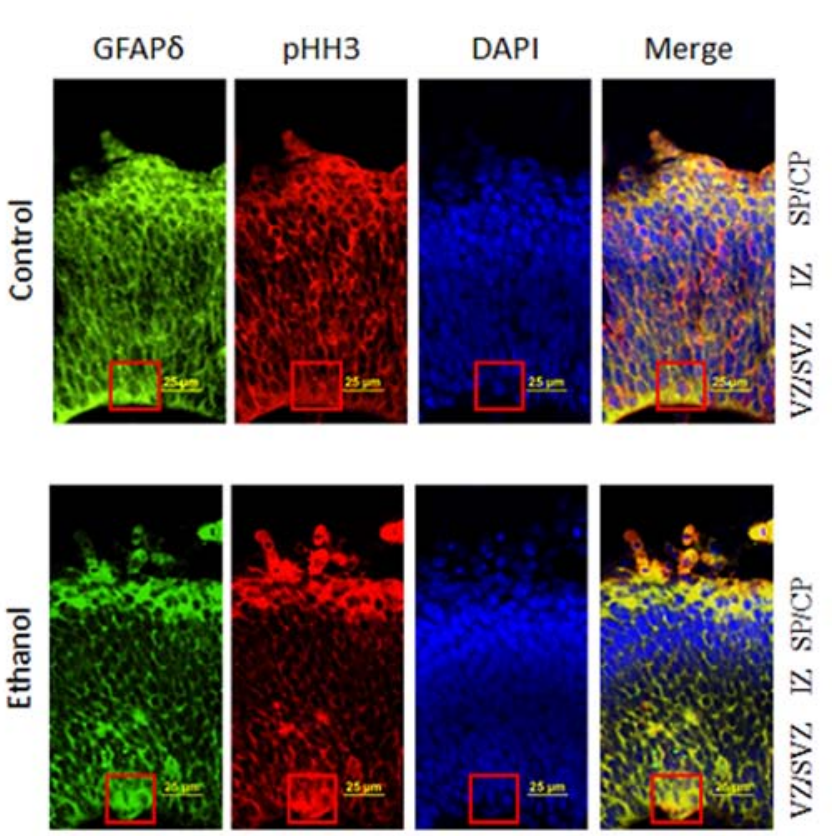
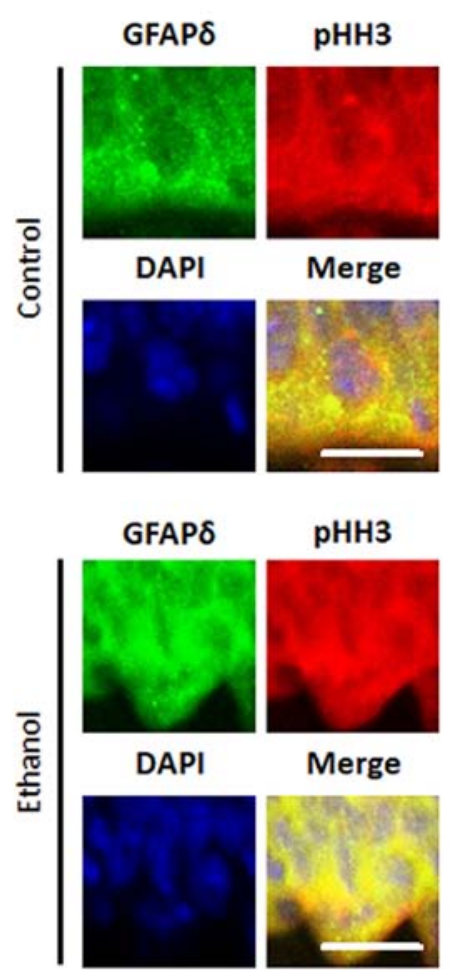

B

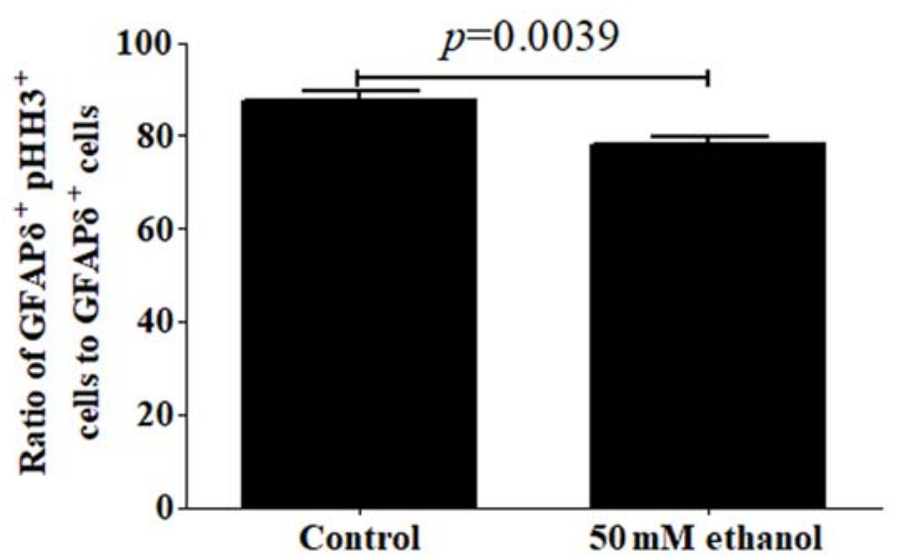

Figure 7. Effect of PEE on the mitotic activities in GFAPd ${ }^{+}$radial glial cells. (A) In embryonic day 14.5 cortices, co-labeling for GFAPd and pHH3 indicated that $\mathrm{GFAPS}^{+}$cells were mitotic RGCs in the VZ, SVZ, IZ or CP. (B) PEE significantly influenced the distribution of GFAP ${ }^{+} \mathrm{pHH}^{+}$cells. In the ethanol cortex, radial glial cells were less abundant for $\mathrm{GFAPS}^{+} \mathrm{pHH} 3^{+}$cells, especially in $\mathrm{SVZ}$ and IZ layers. The representative mitotic cells by co-immunostaining of GFAPS and pHH3 in the control and ethanol-treated cortex are showed in the right magnified images. Scale bar, $25 \mu \mathrm{m}$ (left image) and $20 \mu \mathrm{m}$ (right magnification images). The P-value was obtained from an unpaired Student's t-test. PEE, prenatal ethanol exposure; GFAP, glial fibrillary acidic protein; SP, subcortical plate; CP, cortical plate; IZ, intermediate zone; VZ, ventricular zone; SVZ, subventricular zone; LV, lateral ventricle; pHH3, phospho-histone H3.

network, which is closely associated with cell morphology and cell motility (59).

GFAP $\delta$ and the GFAP expression are first observed at around gestational week 13 in the human fetal brain (41). In 2010, Middeldorp et al (41) first confirmed that GFAPd was specifically found in radial glia and SVZ neural progenitors during human brain development. The GFAP transcript is first detectable at E9.5 in mice embryonic cortex, earlier than the corresponding time for a human (55). During the developmental process, GFAP expression continuously increases until a plateau arrives in the adult brain. In the second trimester, differentiated astrocytes from radial glia are observed in the germinal layers, corpus callosum and cavum septum pellucidum (61). However, it remains unknown what roles GFAPס serves in the transition of RGCs into astrocytes. The present study found that PEE could markedly decrease the intensities of GFAP and GFAPS, indicating that ethanol might impair the development of radial glial fibres and influence the supportive role for the migrating neuroblasts.

Nestin is a class VI intermediate filament protein that is expressed in the majority of mitotically active neural progenitors, including RGCs, which produce both neurons and astrocytes in the developing CNS (62). After differentiation, Nestin expression is downregulated. Using immunostaining, the present study identified that the majority of Nestin labeled RGCs were confined to the VZ and SVZ. Hence, Nestin was considered a marker of NSCs. Using Nestin ${ }^{-1-}$ mice, Wilhelmsson et al (63) confirmed that Nestin negatively 
regulated neuronal differentiation and survival through its role in Notch signaling. Further experiments demonstrated that Nestin was co-expressed with GFAP during the transitional differentiation process of the neural progenitors into astrocytes (64) or neurons (65). The increased colocalization of GFAP and Nestin is a feature of reactive astrocytes (64). NSCs expressing both GFAP and Nestin were termed stem astrocytes (63). The Nestin ${ }^{+} \mathrm{GFAP}^{+}$double labeling of neural progenitors may assist in determining the status of neural progenitors and their differentiation direction. In the present study, ethanol treatment significantly decreased both Nestin and GFAPS expression levels in the SVZ. The co-expression of Nestin and GFAPS expression was also decreased by ethanol treatment. These results indicated that ethanol treatment influenced the stem cell potential of oRG and their morphologies.

Vimentin (also known as nanofilament) is another intermediate filament protein expressed in neural stem/progenitor cells and astrocytes $(41,55)$. Its phosphorylation is an important step required for the organization of the intermediate filament network and the subcellular distribution of its proteins (66-68). Mutations of Vimentin not only alter the cell morphology, proliferative abilities and motility but are also closely associated with alterations in neuronal differentiation of neural progenitor cells and neurogenesis (67). In astrocytes and RGCs, Vimentin forms an intermediate filament complex with GFAP and Nestin. The absence of GFAP and Vimentin could decrease Notch signaling and further increase neuronal differentiation $(67,69)$. A recent report by Cunningham et al $(70)$ revealed that all mitotic cells at the surface of the ventricle in the human and non-human primate dorsal telencephalon express GFAP and Vimentin. Following differentiation into astrocytes, RGCs stop expressing Vimentin and continually upregulate GFAP expression, which suggests that intermediate filament proteins can be transformed during the process of differentiation (67). In the present study, ethanol treatment accelerated the downregulation of Vimentin and promoted the appearance of GFAP $\beta^{+}$cells.

HOPX is the smallest Homeodomain-only protein, which was identified as a temporally and spatially restricted gene in the neurogenic regions in the developing medial cortex and cortical hemisphere at a certain period during the process of neurogenesis (71). Using in situ hybridization, the HOPX gene was first detected at E12.5 forebrains in the most medial part of the cortex. From E14.5 to E16.5, HOPX expression in the forebrain increased from a low level at E14.5 to its peak at E16.5 (71). Thus, HOPX expression exhibits an expression gradient at a high level in the cortical VZ and a low level in the lateral caudal forebrain. In the dorsal forebrain, HOPX expression begins at E12.5 and reaches a peak at $\sim$ E16.5 with a rostromedial to the caudolateral gradient (71). At the same timepoint, RGCs are gradually produced. Several molecular markers including GFAP, SOX2 and Nestin are expressed in quiescent NSCs of this sub-region (71). Moreover, HOPX can be specifically expressed in slow-cycling or quiescent NSCs together with GFAP, Nestin and SOX2, but is not co-expressed with transit-amplifying cell progenitor markers, such as T-box brain protein 2 or the neuroblast marker Doublecortin (72). The aforementioned studies suggested that HOPX may modulate neurogenesis and self-renewal of neural stem cells. Furthermore, the present study demonstrated that ethanol treatment reduced the intensity of HOPX staining in $\mathrm{GFAP \delta}^{+}$cells.

The $S 100 \beta$ protein is an acidic calcium-binding protein that can be expressed both in differentiated and undifferentiated proliferating glial cells (73). Additionally, $\mathrm{S} 100 \beta$ is regarded as a classical astrocyte marker, which suggests that $\mathrm{S} 100 \beta$ expression characterizes a terminal maturation stage (48). During embryonic neurodevelopment, the dynamic expression of S100 $\beta$ in NSCs and RGCs is associated with the proliferative potential and the migration of neural progenitors (73). A previous study reported that the SVZ microenvironment can repress S100 $\beta$ expression (48). Using transgenic S100 $\beta$-EGFP cells, Raponi et al (48) confirmed that $S 100 \beta$ expression defined a late neurodevelopmental stage coinciding with the loss of their stem cell potency. RGCs, as a type of neural stem cell, share certain similar characteristics with immature and mature astrocytes and one of these characteristics is the expression of the intermediate filament GFAP (38). Hence, RGCs have both neurogenic and gliogenic abilities during the development of the embryonic forebrain (74). The onset of $\mathrm{S} 100 \beta$ expression can be regarded as the acquisition of a more mature developmental stage-related to spatiotemporal maturation and the loss of neural stem cell potential (48). Amongst its multiple functions, $\mathrm{S} 100 \beta$ has been identified as a promoter of cytoskeletal stabilization, which serves an important role in normal corticogenesis (75). Decreased GFAP expression may impair the formation of filament complexes together with Nestin and further disrupt the supportive roles in the process of neuronal migration. Co-expression of Nestin and S100 $\beta$ or Nestin and GFAP may indicate that $\mathrm{S}_{100} \beta^{+}$or $\mathrm{GFAP}^{+} \mathrm{RGCs}$ exhibit more restricted developmental potential, and are capable of differentiating into glial cells directed by factors in the local environment (65). In the present study, GFAPd ${ }^{+}$cells exhibited a strong intensity of $\mathrm{S} 100 \beta$ expression following ethanol treatment, which indicated that ethanol promoted the transformation of RGCs into astrocytes.

$\mathrm{Ki67}$ is a nuclear protein, which is used as a marker for identifying dividing cells. It can label cells in the late $\mathrm{G}_{1}, \mathrm{~S}, \mathrm{G}_{2}$ and $M$ phases, but not the $G_{0}$ phase of the cell cycle $(76,77)$. $\mathrm{pHH} 3$ is a proliferation marker that is closely associated with mitotic chromatin condensation in the late $G_{2}$ and $M$ phases of the cell cycle and HH3 is not phosphorylated during apoptosis (78). Compared with $\mathrm{Ki67,} \mathrm{PHH} 3$ is a more reproducible proliferation and mitosis-specific marker (77). The results of the present study demonstrated that ethanol treatment notably inhibited the proliferative and mitotic activities of GFAPd ${ }^{+}$ cells, which contributed to the decreased production of neurons or intermediate progenitor cells and impaired cortical thickness.

In summary, to the best of our knowledge, the present study was the first to identify the effects of prenatal alcohol exposure on the expression and distribution of GFAP during

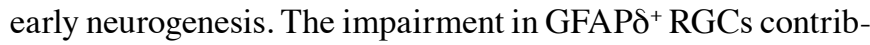
uted to prenatal alcohol exposure-induced abnormal cortical development. Although the mechanisms have not fully been elucidated, the results suggested that the regulation of GFAPD may highlight a novel direction for the treatment and management of prenatal alcohol exposure associated with abnormal cortical development. 


\section{Acknowledgements}

Not applicable.

\section{Funding}

This work was supported by grants from the Key Research and Development Foundation of Shaanxi Province, China (grant no. 2018SF-029), National Natural Science Foundation of China (grant no. 81760441; Principal Investigator, XLD) and Xi'an Science and Technology Plan Project [grant no. 20YXYJ0009(11)].

\section{Availability of data and materials}

The datasets used and/or analyzed during the current study are available from the corresponding author on reasonable request.

\section{Authors' contributions}

YL, FYX and HZ designed the experimental plan. YL, LNZ, LC and YL performed the experiments. YL analysed the data and wrote the manuscript. FYX, HZ and XLD was the principal investigator and revised the manuscript. All authors read and approved the final version of the manuscript and agree to take responsibility for the published article.

\section{Ethics approval and consent to participate}

All animal maintenance and experimental procedures were approved by the Institutional Animal Care and Use Committee of Xi'an Medical University and animal experiments were performed in accordance with the National Institute of Health Guide for the Care and Use of Laboratory Animals (NIH Publications No. 80-23).

\section{Patient consent for publication}

Not applicable.

\section{Competing interests}

The authors declare that they have no competing interests.

\section{References}

1. Popova S, Lange S, Probst C, Gmel G and Rehm J: Estimation of national, regional, and global prevalence of alcohol use during pregnancy and fetal alcohol syndrome: A systematic review and meta-analysis. Lancet Global health 5: e290-e299, 2017.

2. Popova S, Lange S, Probst C, Parunashvili N and Rehm J: Prevalence of alcohol consumption during pregnancy and Feta Alcohol Spectrum Disorders among the general and Aboriginal populations in Canada and the United States. Eur J Med Genet 60 32-48, 2017.

3. Riley EP, Infante MA and Warren KR: Fetal alcohol spectrum disorders: An overview. Neuropsychol Rev 21: 73-80, 2011.

4. Wilhoit LF, Scott DA and Simecka BA: Fetal alcohol spectrum disorders: Characteristics, complications, and treatment Community Ment Health J 53: 711-718, 2017.

5. Petrelli B, Weinberg J and Hicks GG: Effects of prenatal alcohol exposure (PAE): Insights into FASD using mouse models of PAE. Biochem Cell Biol 96: 131-147, 2018.
6. Davis-Anderson KL, Wesseling H, Siebert LM, Lunde-Young ER, Naik VD, Steen H and Ramadoss J: Fetal regional brain protein signature in FASD rat model. Reprod Toxicol 76: 84-92, 2018.

7. Creeley CE, Dikranian KT, Johnson SA, Farber NB and Olney JW: Alcohol-induced apoptosis of oligodendrocytes in the fetal macaque brain. Acta Neuropathol Commun 1: 23, 2013.

8. Farber NB, Creeley CE and Olney JW: Alcohol-induced neuroapoptosis in the fetal macaque brain. Neurobiol Dis 40: 200-206, 2010.

9. Gerlai R: Embryonic alcohol exposure: Towards the development of a zebrafish model of fetal alcohol spectrum disorders. Dev Psychobiol 57: 787-798, 2015.

10. Flentke GR and Smith SM: The avian embryo as a model for fetal alcohol spectrum disorder. Biochem Cell Biol 96: 98-106, 2018.

11. Popova S, Lange S, Probst C, Gmel G and Rehm J: Global prevalence of alcohol use and binge drinking during pregnancy, and fetal alcohol spectrum disorder. Biochem Cell Biol 96: 237-240, 2018.

12. Cheng HG, Deng F, Xiong W and Phillips MR: Prevalence of alcohol use disorders in mainland China: A systematic review. Addiction 110: 761-774, 2015.

13. Wang YY and D'Amato RC: Understanding fetal alcohol spectrum disorders in China. J Pediatr Neuropsychol 3: 53-60, 2017.

14. Clarren SK, Alvord EC Jr, Sumi SM, Streissguth AP and Smith DW: Brain malformations related to prenatal exposure to ethanol. J Pediatr 92: 64-67, 1978.

15. Miller MW: Migration of cortical neurons is altered by gestational exposure to ethanol. Alcohol Clin Exp Res 17: 304-314, 1993.

16. Lotfullina $\mathrm{N}$ and Khazipov R: Ethanol and the developing brain: Inhibition of neuronal activity and neuroapoptosis. Neuroscientist 24: 130-141, 2018.

17. Sowell ER, Mattson SN, Kan E, Thompson PM, Riley EP and Toga AW: Abnormal cortical thickness and brain-behavior correlation patterns in individuals with heavy prenatal alcohol exposure. Cereb Cortex 18: 136-144, 2008.

18. Zhou D, Lebel C, Lepage C, Rasmussen C, Evans A, Wyper K, Pei J, Andrew G, Massey A, Massey D and Beaulieu C: Developmental cortical thinning in fetal alcohol spectrum disorders. NeuroImage 58: 16-25, 2011.

19. Kang W, Wong LC, Shi SH and Hébert JM: The transition from radial glial to intermediate progenitor cell is inhibited by FGF signaling during corticogenesis. J Neurosci 29: 14571-14580, 2009.

20. Segklia A, Seuntjens E, Elkouris M, Tsalavos S, Stappers E, Mitsiadis TA, Huylebroeck D, Remboutsika E and Graf D: Bmp7 regulates the survival, proliferation, and neurogenic properties of neural progenitor cells during corticogenesis in the mouse. PLoS One 7: e34088, 2012.

21. Choe Y, Huynh T and Pleasure SJ: Migration of oligodendrocyte progenitor cells is controlled by transforming growth factor $\beta$ family proteins during corticogenesis. J Neurosci 34: 14973-14983, 2014.

22. Tiberi L, Vanderhaeghen $P$ and van den Ameele J: Cortical neurogenesis and morphogens: Diversity of cues, sources and functions. Curr Opin Cell Biol 24: 269-276, 2012.

23. Bengoa-Vergniory N and Kypta RM: Canonical and noncanonical Wnt signaling in neural stem/progenitor cells. Cell Mol Life Sci 72: 4157-4172, 2015.

24. Inestrosa NC and Varela-Nallar L: Wnt signalling in neuronal differentiation and development. Cell Tissue Res 359: 215-223, 2015.

25. Razavi MJ, Zhang T, Chen H, Li Y, Platt S, Zhao Y, Guo L, Hu X, Wang X and Liu T: Radial structure scaffolds convolution patterns of developing cerebral cortex. Front Comput Neurosci 11: 76, 2017.

26. Yamamoto H, Mandai K, Konno D, Maruo T, Matsuzaki F and Takai Y: Impairment of radial glial scaffold-dependent neuronal migration and formation of double cortex by genetic ablation of afadin. Brain Res 1620: 139-152, 2015.

27. Falk S and Götz M: Glial control of neurogenesis. Curr Opin Neurobiol 47: 188-195, 2017.

28. Yuzwa SA and Miller FD: Deciphering cell-cell communication in the developing mammalian brain. Neurogenesis (Austin) 4: e1286425, 2017.

29. Miller MW and Robertson S: Prenatal exposure to ethanol alters the postnatal development and transformation of radial glia to astrocytes in the cortex. J Comp Neurol 337: 253-266, 1993. 
30. Rubert G, Miñana R, Pascual M and Guerri C: Ethanol exposure during embryogenesis decreases the radial glial progenitorpool and affects the generation of neurons and astrocytes. J Neurosci Res 84: 483-496, 2006.

31. Vallés S, Pitarch J, Renau-Piqueras J and Guerri C: Ethanol exposure affects glial fibrillary acidic protein gene expression and transcription during rat brain development. J Neurochem 69: 2484-2493, 1997.

32. Nash R, Krishnamoorthy M, Jenkins A and Csete M: Human embryonic stem cell model of ethanol-mediated early developmental toxicity. Exp Neurol 234: 127-135, 2012.

33. Johansson PA, Cappello S and Götz M: Stem cells niches during development-lessons from the cerebral cortex. Curr Opin Neurobiol 20: 400-407, 2010.

34. Götz M, Hartfuss E and Malatesta P: Radial glial cells as neuronal precursors: A new perspective on the correlation of morphology and lineage restriction in the developing cerebral cortex of mice. Brain Res Bull 57: 777-788, 2002.

35. Malatesta P, Appolloni I and Calzolari F: Radial glia and neural stem cells. Cell Tissue Res 331: 165-178, 2008

36. Jinnou H, Sawada M, Kawase K, Kaneko N, Herranz-Pérez V, Miyamoto T, Kawaue T, Miyata T, Tabata Y, Akaike T, et al: Radial glial fibers promote neuronal migration and functional recovery after neonatal brain injury. Cell Stem Cell 22: 128-137. e9, 2018.

37. Nowakowski TJ, Pollen AA, Sandoval-Espinosa C and Kriegstein AR: Transformation of the radial glia scaffold demarcates two stages of human cerebral cortex development. Neuron 91: 1219-1227, 2016.

38. Barry DS, Pakan JM and McDermott KW: Radial glial cells: Key organisers in CNS development. Int J Biochem Cell Biol 46 76-79, 2014.

39. Garcia AD, Doan NB, Imura T, Bush TG and Sofroniew MV: GFAP-expressing progenitors are the principal source of constitutive neurogenesis in adult mouse forebrain. Nat Neurosci 7 : 1233-1241, 2004.

40. Johnson K, Barragan J, Bashiruddin S, Smith CJ, Tyrrell C, Parsons MJ, Doris R, Kucenas S, Downes GB, Velez CM, et al: Gfap-positive radial glial cells are an essential progenitor population for later-born neurons and glia in the zebrafish spinal cord. Glia 64: 1170-1189, 2016.

41. Middeldorp J, Boer K, Sluijs JA, De Filippis L, Encha-Razavi F, Vescovi AL, Swaab DF, Aronica E and Hol EM: GFAPdelta in radial glia and subventricular zone progenitors in the developing human cortex. Development 137: 313-321, 2010.

42. Gotoh H, Nomura T and Ono K: Glycogen serves as an energy source that maintains astrocyte cell proliferation in the neonatal telencephalon. J Cereb Blood Flow Metab 37: 2294-2307, 2017.

43. National Research Council: Guide for the Care and Use of Laboratory Animals: 8th edition. The National Academies Press, Washington, DC, 2011.

44. Parnell SE, Chen SY, Charness ME, Hodge CW, Dehart DB and Sulik KK: Concurrent dietary administration of D-SAL and ethanol diminishes ethanol's teratogenesis. Alcohol Clin Exp Res 31: 2059-2064, 2007.

45. Parnell SE, Dehart DB, Wills TA, Chen SY, Hodge CW, Besheer J, Waage-Baudet HG, Charness ME and Sulik KK: Maternal oral intake mouse model for fetal alcohol spectrum disorders: Ocular defects as a measure of effect. Alcohol Clin Exp Res 30: 1791-1798, 2006.

46. Dunn KW, Kamocka MM and McDonald JH: A practical guide to evaluating colocalization in biological microscopy. Am J Physiol Cell Physiol 300: C723-C742, 2011.

47. Pekny M and Pekna M: Astrocyte intermediate filaments in CNS pathologies and regeneration. J Pathol 204: 428-437, 2004.

48. Raponi E, Agenes F, Delphin C, Assard N, Baudier J, Legraverend C and Deloulme JC: S100B expression defines a state in which GFAP-expressing cells lose their neural stem cell potential and acquire a more mature developmental stage. Glia 55: 165-177, 2007.

49. Hutton SR and Pevny LH: SOX2 expression levels distinguish between neural progenitor populations of the developing dorsal telencephalon. Dev Biol 352: 40-47, 2011.

50. Kamachi Y and Kondoh H: Sox proteins: Regulators of cell fate specification and differentiation. Development 140: 4129-4144, 2013.

51. Bani-Yaghoub M, Tremblay RG, Lei JX, Zhang D, Zurakowski B, Sandhu JK, Smith B, Ribecco-Lutkiewicz M, Kennedy J, Walker PR and Sikorska M: Role of Sox 2 in the development of the mouse neocortex. Dev Biol 295: 52-66, 2006.
52. Ferri A, Favaro R, Beccari L, Bertolini J, Mercurio S, Nieto-Lopez F, Verzeroli C, La Regina F, De Pietri Tonelli D, Ottolenghi S, et al: Sox2 is required for embryonic development of the ventral telencephalon through the activation of the ventral determinants Nkx2.1 and Shh. Development 140: 1250-1261, 2013.

53. Hagey DW and Muhr J: Sox 2 acts in a dose-dependent fashion to regulate proliferation of cortical progenitors. Cell Rep 9: 1908-1920, 2014

54. Wang S, Chandler-Militello D, Lu G, Roy NS, Zielke A, Auvergne R, Stanwood N, Geschwind D, Coppola G, Nicolis SK, et al: Prospective identification, isolation, and profiling of a telomerase-expressing subpopulation of human neural stem cells, using sox 2 enhancer-directed fluorescence-activated cell sorting. J Neurosci 30: 14635-14648, 2010.

55. Mamber C, Kamphuis W, Haring NL, Peprah N, Middeldorp J and Hol EM: GFAPס expression in glia of the developmental and adolescent mouse brain. PLoS One 7: e52659, 2012.

56. Kamphuis W, Mamber C, Moeton M, Kooijman L, Sluijs JA, Jansen AH, Verveer M, de Groot LR, Smith VD, Rangarajan S, et al: GFAP isoforms in adult mouse brain with a focus on neurogenic astrocytes and reactive astrogliosis in mouse models of Alzheimer disease. PLoS One 7: e42823, 2012.

57. Yang Z and Wang KK: Glial fibrillary acidic protein: From intermediate filament assembly and gliosis to neurobiomarker. Trends Neurosci 38: 364-374, 2015.

58. Howard BM, Zhicheng M, Filipovic R, Moore AR, Antic SD and Zecevic N: Radial glia cells in the developing human brain. Neuroscientist 14: 459-473, 2008.

59. Sullivan SM: GFAP variants in health and disease: Stars of the brain... and gut. J Neurochem 130: 729-732, 2014.

60. Zalfa C, Grasselli C, Santilli G, Ferrari D, Lamorte G, Vescovi AL and De Filippis L: GFAP delta as divergent marker of human glial progenitors. J Stem Cell Res Ther 8: 9, 2018.

61. Rezaie P, Ulfig N and Male D: Distribution and morphology of GFAP-positive astrocytes in the human fetal brain at second trimester. Neuroembryology 2: 50-63, 2003.

62. Sunabori T, Tokunaga A, Nagai T, Sawamoto K, Okabe M, Miyawaki A, Matsuzaki Y, Miyata T and Okano $\mathrm{H}$ : Cell-cycle-specific nestin expression coordinates with morphological changes in embryonic cortical neural progenitors. J Cell Sci 121: 1204-1212, 2008.

63. Wilhelmsson U, Lebkuechner I, Leke R, Marasek P, Yang X, Antfolk D, Chen M, Mohseni P, Lasič E, Bobnar ST, et al: Nestin regulates neurogenesis in mice through notch signaling from astrocytes to neural stem cells. Cereb Cortex 29: 4050-4066, 2019.

64. Messam CA, Hou J and Major EO: Coexpression of nestin in neural and glial cells in the developing human CNS defined by a human-specific anti-nestin antibody. Exp Neurol 161: 585-596, 2000.

65. Vukojevic K, Petrovic D and Saraga-Babic M: Nestin expression in glial and neuronal progenitors of the developing human spinal ganglia. Gene Expr Patterns 10: 144-151, 2010.

66. Eriksson JE, He T, Trejo-Skalli AV, Härmälä-Braskén AS, Hellman J, Chou YH and Goldman RD: Specific in vivo phosphorylation sites determine the assembly dynamics of vimentin intermediate filaments. J Cell Sci 117: 919-932, 2004.

67. Chen M, Puschmann TB, Marasek P, Inagaki M, Pekna M, Wilhelmsson U and Pekny M: Increased neuronal differentiation of neural progenitor cells derived from phosphovimentin-deficient mice. Mol Neurobiol 55: 5478-5489, 2018.

68. Chou YH, Khuon S, Herrmann H and Goldman RD: Nestin promotes the phosphorylation-dependent disassembly of vimentin intermediate filaments during mitosis. Mol Biol Cell 14: $1468-1478,2003$

69. Widestrand A, Faijerson J, Wilhelmsson U, Smith PL, Li L, Sihlbom C, Eriksson PS and Pekny M: Increased neurogenesis and astrogenesis from neural progenitor cells grafted in the hippocampus of $\mathrm{GFAP}^{-/-} \mathrm{Vim}^{-/-}$mice. Stem Cells 25: 2619-2627, 2007.

70. Cunningham CL, Martinez-Cerdeno V and Noctor SC: Diversity of neural precursor cell types in the prenatal macaque cerebral cortex exists largely within the astroglial cell lineage. PLoS One 8: e63848, 2013.

71. Li D, Takeda N, Jain R, Manderfield LJ, Liu F, Li L, Anderson SA and Epstein JA: Hopx distinguishes hippocampal from lateral ventricle neural stem cells. Stem Cell Res 15: 522-529, 2015.

72. Braun SM and Jessberger S: Adult neurogenesis: Mechanisms and functional significance. Development 141: 1983-1986, 2014. 
73. Patro N, Naik A and Patro IK: Differential temporal expression of S100 $\beta$ in developing rat brain. Front Cell Neurosci 9: 87, 2015.

74. Docampo-Seara A, Santos-Durán GN, Candal E and Rodríguez Díaz MÁ: Expression of radial glial markers (GFAP, BLBP and GS) during telencephalic development in the catshark (Scyliorhinus canicula). Brain Struct Funct 224: 33-56, 2019.

75. Aronne MP, Guadagnoli T, Fontanet P, Evrard SG and Brusco A: Effects of prenatal ethanol exposure on rat brain radial glia and neuroblast migration. Exp Neurol 229: 364-371, 2011.

76. Malik S, Vinukonda G, Vose LR, Diamond D, Bhimavarapu BB, Hu F, Zia MT, Hevner R, Zecevic N and Ballabh P: Neurogenesis continues in the third trimester of pregnancy and is suppressed by premature birth. J Neurosci 33: 411-423, 2013.
77. Zhang $\mathrm{J}$ and Jiao $\mathrm{J}$ : Molecular biomarkers for embryonic and adult neural stem cell and neurogenesis. Biomed Res Int 2015: 727542,2015

78. van den Berge SA, van Strien ME, Korecka JA, Dijkstra AA, Sluijs JA, Kooijman L, Eggers R, De Filippis L, Vescovi AL, Verhaagen $\mathrm{J}$, et al: The proliferative capacity of the subventricular zone is maintained in the parkinsonian brain. Brain 134: 3249-3263, 2011

c) (i) $(9)$ This work is licensed under a Creative Commons EY NG NO Attribution-NonCommercial-NoDerivatives 4.0 International (CC BY-NC-ND 4.0) License. 